\title{
Passive control of temperature fluctuations through a sunlight- induced spin transition in a molecule-based material
}

Esther Resines-Urien, ${ }^{1}$ Miguel Ángel García García-Tuñón, ${ }^{2}$ Mar Garcia-Hernandez, ${ }^{3}$ J. Alberto Rodríguez-Velamazán, ${ }^{4}$ Ana Espinosa, ${ }^{1 *}$ Jose Sanchez Costa ${ }^{1 *}$

${ }^{1}$ IMDEA Nanociencia; C/ Faraday 9, 28049, Madrid, Spain.

${ }^{2}$ Instituto de Cerámica y Vidrio; CSIC, C/Kelsen s/n, 28240, Madrid, Spain.

${ }^{3}$ Instituto de Ciencia de Materiales de Madrid, CSIC; C/Sor Juana Inés de la Cruz, 3, 28049, Madrid, Spain.

${ }^{4}$ Institut Laue-Langevin; 71 avenue des Martyrs, BP 156, 38042 Grenoble Cedex 9, France.

*Email: ana.espinosa@imdea.org; jose.sanchezcosta@imdea.org

\begin{abstract}
The increasing environmental protection demand has prompted the development of passive thermal regulation systems that reduce temperature fluctuations in buildings. Here, we demonstrate that the heat generated by the sun can trigger a spin transition in a spin crossover (SCO) material, resulting in a color change. This leads to a cooling effect in respect to other similar materials, due to an increase in light reflection. In addition, when the material is cooled, a dampening of the temperature decrease is produced. Therefore, these materials could potentially be implemented for passive temperature control in buildings. Furthermore, SCO materials are remarkably stable upon cycling and highly versatile, which allows for the design of compounds with properties tailored for the desired climatic conditions and comfort temperature.
\end{abstract}

One-Sentence Summary: The use of spin crossover materials as passive thermal regulation systems can lead to temperature control in both directions.

Nowadays, building thermalization is a widespread human necessity, accounting for $30 \%$ of the total final energy use and $28 \%$ of energy-related $\mathrm{CO}_{2}$ worldwide emissions.(1) These $\mathrm{CO}_{2}$ emissions are a major contributor to climate change, which has become one of the biggest concerns of humankind.(2) A reduction in emissions could be achieved by eliminating coal, oil and natural gas as sources of building heating, and by reducing the energy consumption derived from the use of air conditioning systems.(3) Thus, the growing energy saving demand and environmental protection has prompted the development and implementation of more energy-efficient and environmentally friendly thermalization technology. In this regard, remarkable efforts have been focused on the implementation of passive thermal regulation systems, that can be incorporated directly in the roof or the walls of buildings and operate without the need for electricity.(4-6)

Although to keep buildings cool the light absorption and reflection properties have been used for millennia, nowadays more sophisticated approaches are being explored for passive thermal regulation of buildings. The first one is based on the so-called radiative cooling technique, in which a surface is naturally cooled by reflecting sunlight and radiating heat to the cold outer space.(711) The second approach uses hygroscopic and/or porous materials to store and release water when heated, leading to evaporative cooling, where heat is dissipated through water evaporation.(1216) The last one is the use of phase-change materials (PCMs), which present high-density thermal 
energy storage, therefore minimizing temperature fluctuations through the use of latent heat.(1721)

Employing the first two approaches, subambient cooling was achieved both during the day and night. While this is interesting for places where the weather is hot throughout the whole day, certain regions of the world, with climates where high temperatures are reached during the day and low temperatures at night, for example New Delhi,(22) require different materials to reduce temperature fluctuations in both directions. Therefore, certain PCM are so far applied for thermal regulation in both senses, although they display some limitations. $(23,24)$ Nevertheless, under a global warming perspective, the need to reduce temperature fluctuations calls for the development of new materials and/or novel alternative approaches to tackle this problem in a more effective manner.

In this respect, a new strategy could be the use of materials that combine two of the principles mentioned before by switching between multiple phases that display distinct thermo-induced optical properties, resulting in different light reflection(25-27) One can easily imagine the advantage in thermal efficiency for buildings with a coating that changes color from a clear, reflecting color in summer to a darker, absorbing color in winter, or even in shorter day/night cycles since they could also dampen thermal fluctuations as a consequence of the phase change.

A new approach could be the use of molecule-based switchable spin crossover (SCO) compounds.(28-34) These materials undergo spin transition between two electronic states, low spin (LS) and high spin (HS) upon an external stimuli, including the temperature variation. This spin transition is associated with a color change,(35) which could result in a different capacity for reflecting sunlight (see Figure 1).(36, 37)

The application of SCO materials for thermal management purposes has been considered recently in different contexts. In particular, there have been a few reports about possible barocaloric refrigeration applications $(38-40)$ as well as the use of SCO materials as thermal protective barriers in microelectronic circuits $(41,42)$ and in buildings.(43) However, these ideas consisted in the use of latent heat associated with the SCO, in contrast to the present work, in which we consider primarily the role of thermochromic properties. The key advantage in the use of these switchable materials is that the appropriate selection of a SCO material could result in effective passive temperature control in circumstances were large temperature fluctuations need to be avoided (unlike reflecting coatings, which are only beneficial to reduce warming during sunlight exposure). Moreover, the remarkable versatility of SCO compounds may allow adapting the desired phase change temperature and hysteresis to the climatic conditions and the desired comfort temperature. Therefore, the objective of this work is to give a proof-of-concept of this idea by demonstrating, in the first place, that the heat generated by the solar radiation is enough to produce a spin transition in a SCO material and, secondly, that the use of this material allows, in both heating and cooling, to reduce temperature fluctuations. 
a)

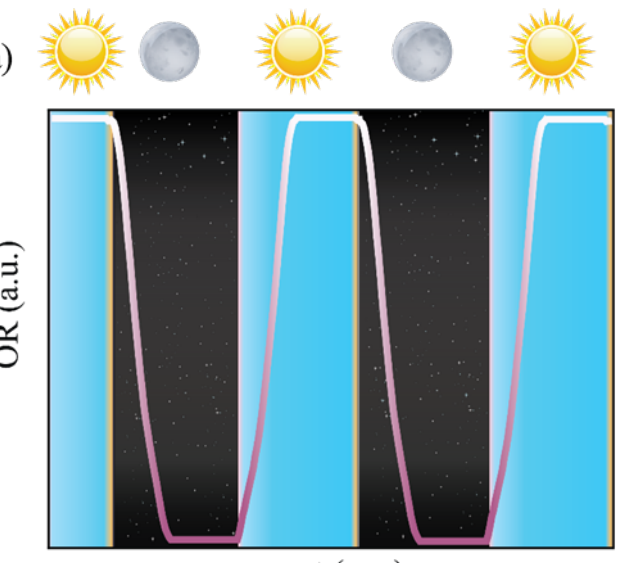

t (a.u.)



c)

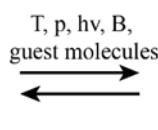

Figure 1. a) Scheme of the behavior of a SCO material during day-night cycles. b) Working scheme of a SCO material under solar radiation. When the weather is hot, and the material is in its HS state (white), the light is reflected and the increase in the temperature of room is controlled. On the contrary, under cold temperatures, the materials shows the LS state (pink), so more wavelengths are absorbed and the room is heated. c) Illustration of the spin transition under external stimuli.

Here, three different molecular-based coordination polymers $\left[\mathrm{Fe}\left(\mathrm{NH}_{2} \mathrm{trz}\right)_{3}\right](\mathrm{OTs})_{2} \quad$ (1), $\left[\mathrm{Fe}(\mathrm{Htrz})_{2}(\operatorname{trz})\left[\left(\mathrm{BF}_{4}\right)_{2}(\mathbf{2})\right.\right.$ and $\left[\mathrm{Zn}\left(\mathrm{NH}_{2} \operatorname{trz}\right)_{3}\right]\left(\mathrm{NO}_{3}\right)_{2}(\mathbf{3})$ have been synthesized, where $\mathrm{NH}_{2} \operatorname{trz}=4-$ Amino-4H-1,2,4-triazole; OTs $=p$-toluenesulfonate; Htrz $=1,2,4$-Triazole and trz $=1,2,4$ triazolate. These materials present the widely studied structure of the family of the triazole-based SCO coordination polymers (Figure S3).(44-46) That is to say, the metal center is in an octahedral environment, coordinated to six nitrogen atoms from six different triazole units. The triazoles act as bridging ligands between two metal centers, leading to the formation of $1 \mathrm{D}$ chains. When Fe(II) is used as the metal center, these materials can exhibit SCO properties. Of particular interest for this work is that compound $\mathbf{1}$ displays the spin transition around room temperature (RT). To investigate and compare the temperature control ability of 1, two different compounds (Figure S2) were synthetized: a compound that is only in its LS state in this temperature range (2), and thus remains pink, and another that is white (3).

To facilitate the use of these powder-like materials, compounds $\mathbf{1 - 3}$ were embedded $(47,48)$ in the organic polymer polymethyl methacrylate (PMMA), from here on 1@PMMA, 2@PMMA, and 3@PMMA, respectively (Figure 2b). Optical and magnetic SCO properties were explored by optical reflectivity (OR) and SQUID magnetometry, both in the coordination polymers and when combined with PMMA (Figure 2c and S3-S9).

As expected, the spin transition properties of 1@PMMA and 2@PMMA compared to 1 and 2 are maintained, with the only difference that the hybrid materials show a gradual transition compared to the powder samples (see Figure S3-S9 for further details). Importantly, this thermochromic process is reversible, and can be maintained for several thermal cycles (see Figure S10 for 40 heating-cooling cycles).(49) Naturally, neither compound 3 nor 3@PMMA display a spin transition, since $\mathrm{Zn}(\mathrm{II})$ is a $\mathrm{d}^{10}$ transition metal, and the possibility of SCO is nonexistent. All these materials were further characterized by Fourier-transform infrared spectroscopy (FTIR), powder X-ray diffraction (PXRD) and thermal gravimetric analysis (TGA) (see Figure S11-21 for further details). These techniques confirm that the desired reported compounds have been obtained.(50, 51) The absorption spectra for 1@PMMA-3@PMMA and PMMA (Figure S22-S25) were 
measured in the temperature range where the experiment takes place. The spectra remain constant with temperature for 2@PMMA,3@PMMA and PMMA, while clear differences can be observed for 1@PMMA. In this case, as the temperature increases, and the composite becomes light pink, the light absorption decreases. This is in agreement with the optical reflectivity measurements.

In order to simulate temperature fluctuations in a room, two different experiments were devised. The first one (Figure 2a and S26) consists on placing the polymers (1@PMMA-3@PMMA and PMMA) on top of an empty glass vial under the irradiation of a solar lamp (sun simulator, 1000 $\mathrm{W} / \mathrm{m}^{2}$ ). This configuration mimics the temperature in a closed room. This process was recorded with an infrared thermal camera, so that the temperature inside the vials and in the polymer could be characterized over time, visualizing their thermal gradients.

The recorded infrared thermal images can be seen in Figure 2d, at times 0 and $600 \mathrm{~s}$ from the start of sunlight irradiation. Four different spots have been measured in relation to the irradiation time (Figure 2e): the sample temperature $\left(\mathrm{T}_{1}\right)$, a temperature inside the vial $\left(\mathrm{T}_{2}\right)$ and two temperatures underneath the vial: one inside the vial $\left(\mathrm{T}_{3}\right)$ and another outside $\left(\mathrm{T}_{4}\right)$.

The sample temperature ( $\mathrm{T}_{1}$, top graph) shows that 2@PMMA increases from $24{ }^{\circ} \mathrm{C}$ to $41.6{ }^{\circ} \mathrm{C}$ $\left(\Delta \mathrm{T}=17.6{ }^{\circ} \mathrm{C}\right)$. Therefore, starting from roughly the same temperature, the 2@PMMA temperature increases $8{ }^{\circ} \mathrm{C}$ more than that of $1 @$ PMMA $\left(\Delta \mathrm{T}=10^{\circ} \mathrm{C}\right)$, and $16^{\circ} \mathrm{C}$ more than in 3@PMMA and PMMA $\left(\Delta \mathrm{T}=1.3^{\circ} \mathrm{C}\right)$. The rate at which the temperature increases in the first two minutes is as follows: 1@PMMA $4{ }^{\circ} \mathrm{C} \cdot \mathrm{min}^{-1}$, 2@PMMA $8{ }^{\circ} \mathrm{C} \cdot \mathrm{min}^{-1}, 3 @ \mathbf{P M M A} 0.5{ }^{\circ} \mathrm{C} \cdot \mathrm{min}^{-1}$ and PMMA $0.4^{\circ} \mathrm{C} \cdot \mathrm{min}^{-1}$.

Upon examination of $\mathrm{T}_{2}$, it can be seen that in all cases, an increase in temperature is observed as the irradiation time progresses, although in 3@PMMA and PMMA the temperature rises significantly less than in the other two. For compounds 1@PMMA and 2@PMMA the temperature increases with time in a similar manner, up to 50 seconds, where the two plots diverge and 2@PMMA heats up more than the SCO sample. More precisely, the temperature in 2@PMMA increases by $14.4 \%$, and by $10.2 \%$ for 1@PMMA, which means a slight control in temperature was achieved.

On the other hand, for $T_{3}$ the greatest thermal increment is observed for 3@PMMA and PMMA. This indicates that the sunlight is able to pass through the white materials and raise the temperature inside the room. 2@PMMA follows as the next sample that reaches the highest temperature on the floor. 
a)

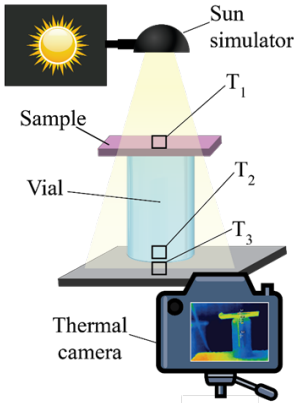

b)
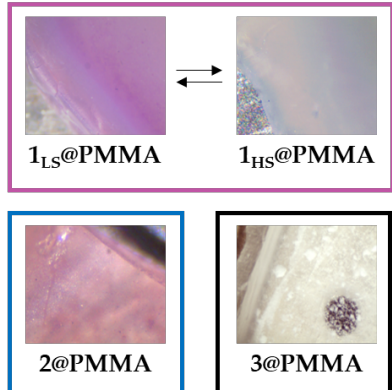

c)
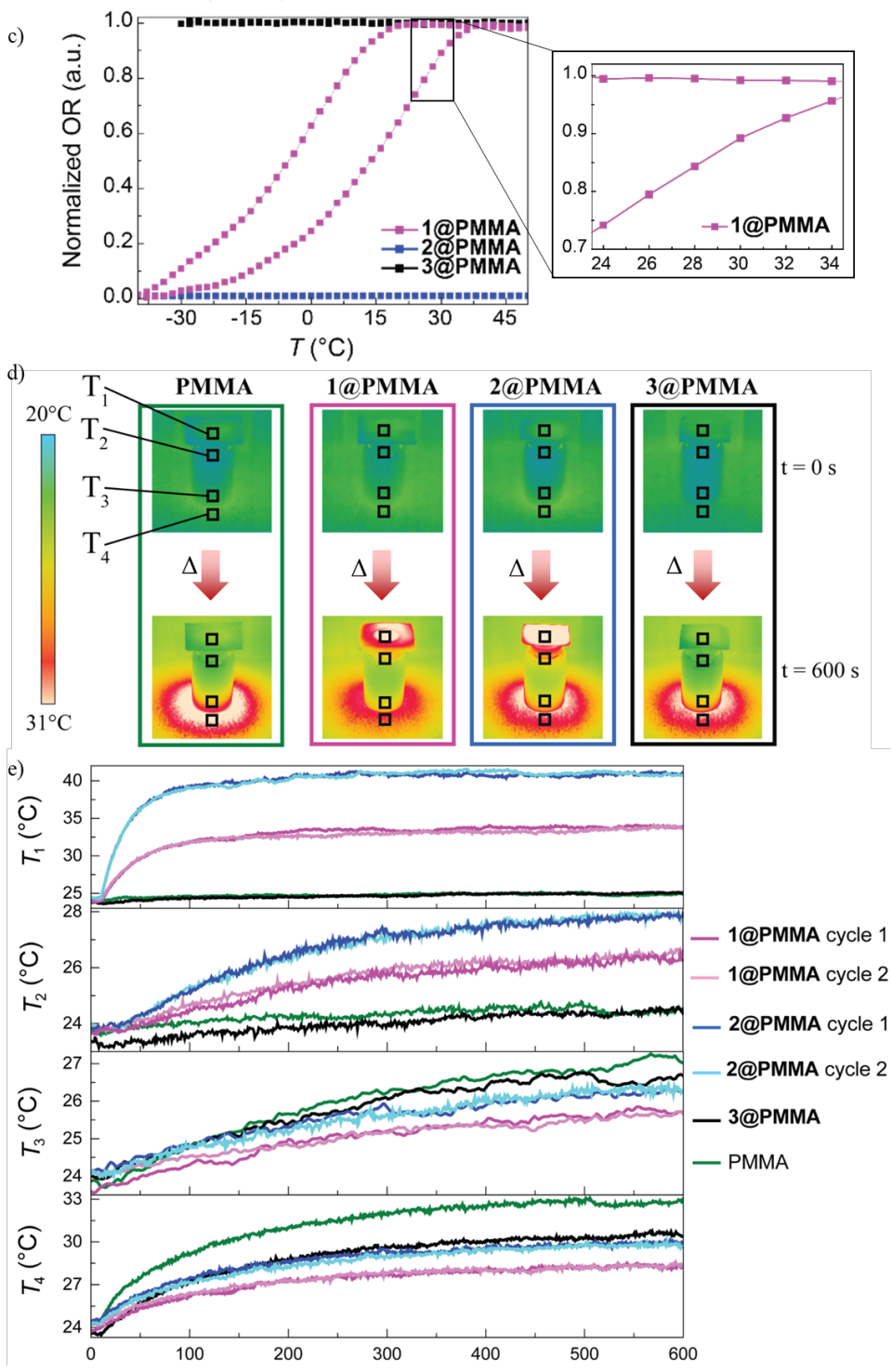

Figure 2. a) Scheme of the experimental setup. b) Images of the composites at the highest and lowest measured temperature. c) Optical reflectivity measurements for 1@PMMA3@PMMA with a zoom for 1@PMMA in the temperature region encompassed by these sunlight exposure measurements. The optical reflectivity has been normalized in respect to 1@PMMA. d) Thermal images for 1@PMMA-3@PMMA and PMMA at time 0 and $600 \mathrm{~s}$ under sunlight exposure. The measured area in each sample is marked with a square in the images. e) Temperature $v s$. exposure time (the sun simulator is turned on after 10 seconds) at the four measured spots. 
Therefore, the tendency: PMMA > 3@PMMA > 2@PMMA > 1@PMMA can be explained by a synergy occurring between two different effects. The first is that the completely white samples do not heat up, but allow solar radiation to pass through and, consequently, the temperature in the room increases.

The opposite effect is observed in the case of 2@PMMA, where the material itself is the one that heats up the most, and results in a temperature increase. This is because dark materials absorb more wavelengths of light and convert them into heat. It is important to note that 1@PMMA is in a bistable region, so it is neither completely white nor as pink as it would be when it is completely in LS. It therefore shows a synergy of these two effects: it starts with a slight pink color, which impedes solar radiation from passing through the material, and becomes almost white, allowing to absorb with less intensity. This same behavior can be observed for $\mathrm{T}_{4}$. To confirm that this behavior can be replicated, the 1@PMMA and 2@PMMA materials were measured twice. In between the measurements, the samples were cooled, so that the materials recover their initial state. For both materials and in the four measured spots, it is evident that the temperature dependence with time is replicable.

The different behaviors between 1@PMMA and 2@PMMA can be explained by plotting the temperature in the 1@PMMA polymer (Figure 2e, upper graph). At the beginning of the measurement, the 1@PMMA film is at $23.8{ }^{\circ} \mathrm{C}$, which according to the optical reflectivity measurements (Figure 2c), corresponds to a $74 \%$ of HS, while by the end of the measurement, the temperature of the composite reaches a maximum of $33.9{ }^{\circ} \mathrm{C}$, where $95 \%$ of the iron centers in the composite are in HS. This indicates that the heat generated by the sun simulator (or the sun itself) is enough to provoke a partial spin transition in the material. As previously discussed, the spin transition from LS to HS results in a color change from pink (LS) to white (HS). Although the spin transition is only partial, a fraction of $21 \%$ of the iron(II) ions changed from LS to HS in this temperature range, which is sufficient for a color change to be seen by the naked-eye (Figure S27). Thus, the material is able to dissipate heat more efficiently than the analogous pink sample 2@PMMA in which the SCO does not occur in this temperature range.

The second setup (Figure 3a and S28) was designed to characterize hot-cold cycles and avoid contributions from conduction and convection (due to sample contact with the vial). Here, the sample is placed between copper foils, that are in contact with two Peltiers (see setup description in the Supporting Information). This enables the sample to be cooled below RT. The polymer is irradiated with the solar lamp, and the temperature fluctuations are measured using an anodized aluminum sensor, placed underneath the sample $\left(\mathrm{T}_{\text {target }}\right)$. The composite temperature is recorded with an infrared thermal camera, and the sensor temperature using a thermocouple.

In Figure 3d, the samples are subjected to hot-cold cycles, simulating day and night conditions. Before starting the experiment, the solar lamp is off and the two Peltier on, to bring the samples at the same temperature (Figure S29) to perform comparable hot-cold cycles. Afterward, the solar simulator is turned on and the Peltier off, which corresponds to the heating process. The two temperatures $\mathrm{T}_{\text {sample }}$ and the $\mathrm{T}_{\text {target }}$ were followed $v s$ the time. 
a)
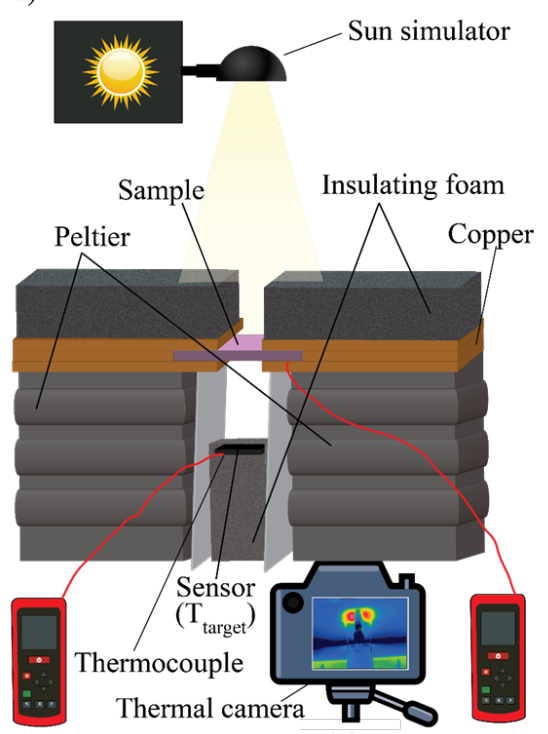

d) b)
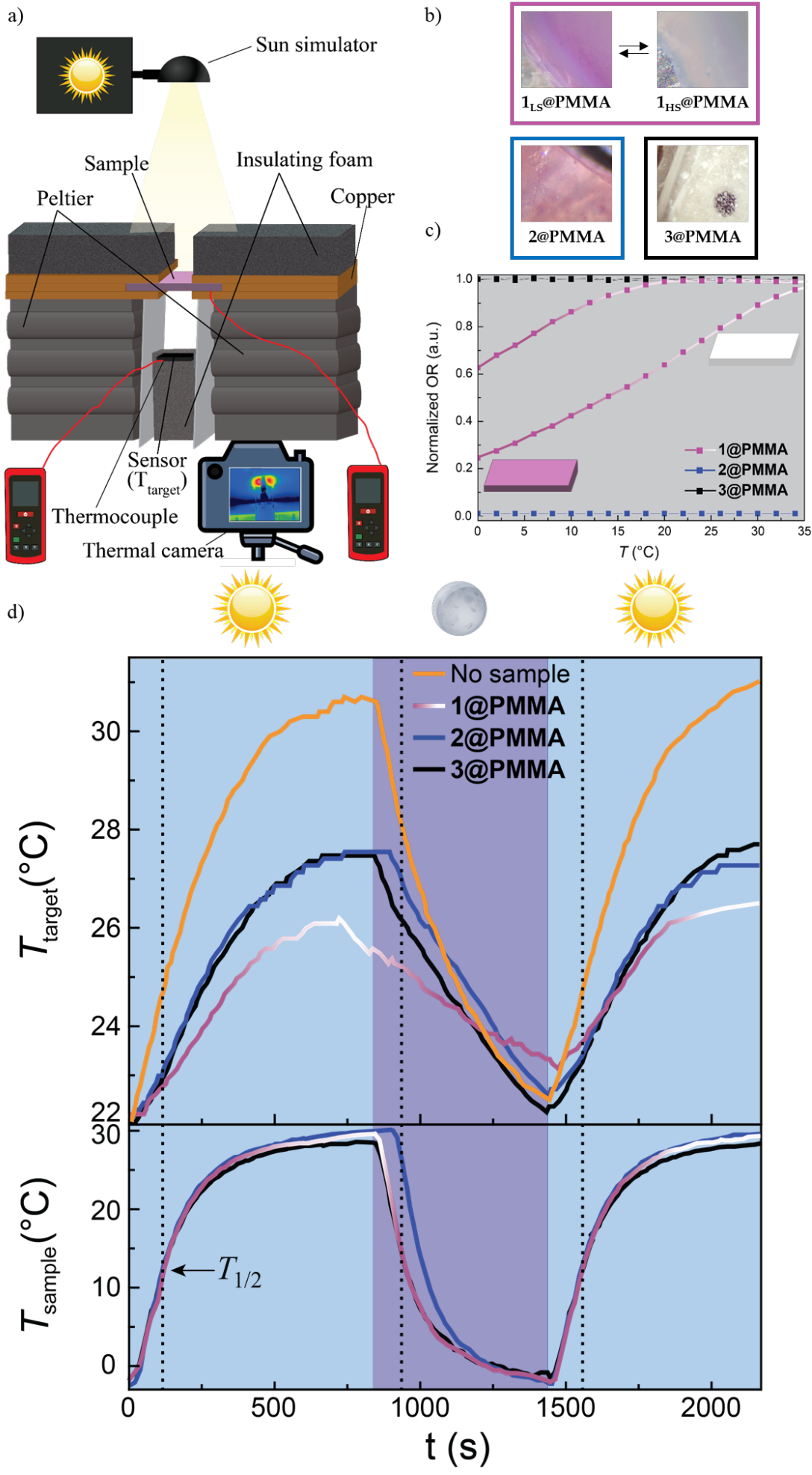

Figure 3. a) Scheme of the experimental setup. b) Images of the composites at the highest and lowest measured temperature. c) Optical reflectivity measurements for 1@PMMA3@PMMA in the temperature region encompassed by these sunlight exposure measurements. The optical reflectivity has been normalized in respect to 1@PMMA. d) Temperature $v s$. exposure time with on-off solar simulator cycles. 
The $\mathrm{T}_{\text {sample }}$ increases following this sequence: 2@PMMA > 1@PMMA > 3@PMMA (Figure S29). However, $T_{\text {target }}$ rises following this 3@PMMA > 2@PMMA > 1@PMMA order. When the experiment is carried out without the presence of a sample, $\mathrm{T}_{\text {target }}$ increases rapidly, reaching the highest temperature.

The cooling cycle starts at time $800 \mathrm{~s}$, when the solar lamp is switched off and the Peltier on (dark blue background). Immediately, both $\mathrm{T}_{\text {sample }}$ and $\mathrm{T}_{\text {target }}$ begin to drop. $\mathrm{T}_{\text {target }}$ reaches a minimum temperature at 1480 s. Interestingly, this minimum is higher for 1@PMMA in respect to the references 2@PMMA and 3@PMMA, and also higher than when no sample is employed.

Again, the system is set in heating mode and the same behavior as in the first cycle is observed: 2@PMMA and 3@PMMA reach higher temperatures than 1@PMMA and the highest temperature is reached when no sample is used. These experiments were repeated, and the same result was obtained (Figure S29).

From the sample temperature, it can be stated that 1@PMMA is shifting from a $22 \%$ of HS Fe(II) ions $\left(\right.$ at $\left.-2{ }^{\circ} \mathrm{C}\right)$, to $88 \%$ of HS at the highest temperature $\left(29.6{ }^{\circ} \mathrm{C}\right)$. This translates into less temperature fluctuations during both cooling and heating, which can be associated with the synergy between thermochromism and phase change derived from its bistable behavior.

In addition, to simulate what would occur upon a temperature decrease under solar irradiation, this same setup was used but, in this case, the solar lamp remains lit during the entire experiment, accompanied by Peltier on-off cycles (Figure S30). At the beginning of the experiment, the Peltier is switched on, resulting in a cooling of the sample, and to some extent, also of the sensor. The main observation here is that the minimum recorded $\mathrm{T}_{\text {target }}\left(25^{\circ} \mathrm{C}\right)$ is reached more slowly for 1@PMMA when in comparison with the references (at times $400 \mathrm{~s}, 750 \mathrm{~s}$ and $910 \mathrm{~s}$, for 2@PMMA, 3@PMMA and 1@PMMA, respectively). When no sample is used, the minimum $\mathrm{T}_{\text {target }}$ recorded is $29^{\circ} \mathrm{C}$. This result reinforces the conclusion that the material exhibiting SCO is capable of reducing temperature fluctuations and providing certain control over the temperature.

\section{Conclusions}

To summarize, this work demonstrates that the heat generated by the sun is sufficient to produce, at least, a partial spin transition in a SCO material. This, in turn, leads to a cooling effect in respect to other similar materials, due to an increase in light reflection resulting from the color change of the SCO. In addition, when the material is cooled to temperatures easily attainable at night $\left(-2^{\circ} \mathrm{C}\right)$, a dampening of the temperature decrease is produced. Here, the material regains its initial behavior and can be employed again to control fluctuations at increasing temperatures. Therefore, this type of materials can be used to reduce temperature fluctuations, which could potentially be implemented for passive temperature control in buildings. SCO molecule-based materials are remarkably stable upon cycling and highly versatile, which may allow for the design of compounds adapting the intended properties (transition temperature and hysteresis) for the climatic conditions and the desired comfort temperature.

1. International Energy Agency, The Critical Role of Buildings, Perspectives for the Clean Energy Transition - Analysis (2020), (available at https:/www.iea.org/reports/the-criticalrole-of-buildings).

2. T. J. Crowley, R. A. Berner, $\mathrm{CO}_{2}$ and climate change. Science. 292, 870-872 (2001).

3. M. O. McLinden, C. J. Seeton, A. Pearson, New refrigerants and system configurations for 
vapor-compression refrigeration. Science. 370, 791-796 (2020).

4. C. G. Granqvist, Solar Energy Materials. Adv. Mater. 15, 1789-1803 (2003).

5. H. Ben Cheikh, A. Bouchair, Passive cooling by evapo-reflective roof for hot dry climates. Renew. Energy. 29, 1877-1886 (2004).

6. Y. ling Song, K. S. Darani, A. I. Khdair, G. Abu-Rumman, R. Kalbasi, A review on conventional passive cooling methods applicable to arid and warm climates considering economic cost and efficiency analysis in resource-based cities. Energy Reports. 7, 27842820 (2021).

7. A. P. Raman, M. A. Anoma, L. Zhu, E. Rephaeli, S. Fan, Passive radiative cooling below ambient air temperature under direct sunlight. Nature. 515, 540-544 (2014).

8. J. Mandal, Y. Fu, A. C. Overvig, M. Jia, K. Sun, N. N. Shi, H. Zhou, X. Xiao, N. Yu, Y. Yang, Hierarchically porous polymer coatings for highly efficient passive daytime radiative cooling. Science. 362, 315-319 (2018).

9. A. Leroy, B. Bhatia, C. C. Kelsall, A. Castillejo-Cuberos, M. H. Di Capua, L. Zhao, L. Zhang, A. M. Guzman, E. N. Wang, High-performance subambient radiative cooling enabled by optically selective and thermally insulating polyethylene aerogel. Sci. Adv. 5, 19 (2019).

10. T. Wang, Y. Wu, L. Shi, X. Hu, M. Chen, L. Wu, A structural polymer for highly efficient all-day passive radiative cooling. Nat. Commun. 12, 1-12 (2021).

11. Z. Huang, X. Ruan, Nanoparticle embedded double-layer coating for daytime radiative cooling. Int. J. Heat Mass Transf. 104, 890-896 (2017).

12. C. Feng, P. Yang, H. Liu, M. Mao, Y. Liu, T. Xue, J. Fu, T. Cheng, X. Hu, H. J. Fan, K. Liu, Bilayer porous polymer for efficient passive building cooling. Nano Energy. 85, 105971 (2021).

13. A. C. C. Rotzetter, C. M. Schumacher, S. B. Bubenhofer, R. N. Grass, L. C. Gerber, M. Zeltner, W. J. Stark, Thermoresponsive polymer induced sweating surfaces as an efficient way to passively cool buildings. Adv. Mater. 24, 5352-5356 (2012).

14. S. Pu, J. Fu, Y. Liao, L. Ge, Y. Zhou, S. Zhang, S. Zhao, X. Liu, X. Hu, K. Liu, J. Chen, Promoting Energy Efficiency via a Self-Adaptive Evaporative Cooling Hydrogel. Adv. Mater. 32, 1907307 (2020).

15. Z. Lu, E. Strobach, N. Chen, N. Ferralis, J. C. Grossman, Passive Sub-Ambient Cooling from a Transparent Evaporation-Insulation Bilayer. Joule. 4, 2693-2701 (2020).

16. D. Zhao, A. Aili, Y. Zhai, J. Lu, D. Kidd, G. Tan, X. Yin, R. Yang, Subambient Cooling of Water: Toward Real-World Applications of Daytime Radiative Cooling. Joule. 3, 111-123 (2019).

17. H. Akeiber, P. Nejat, M. Z. A. Majid, M. A. Wahid, F. Jomehzadeh, I. Zeynali Famileh, J. K. Calautit, B. R. Hughes, S. A. Zaki, A review on phase change material (PCM) for sustainable passive cooling in building envelopes. Renew. Sustain. Energy Rev. 60, 14701497 (2016).

18. M. Kenisarin, K. Mahkamov, Passive thermal control in residential buildings using phase change materials. Renew. Sustain. Energy Rev. 55, 371-398 (2016). 
19. S. Ramakrishnan, X. Wang, J. Sanjayan, J. Wilson, Thermal performance of buildings integrated with phase change materials to reduce heat stress risks during extreme heatwave events. Appl. Energy. 194, 410-421 (2017).

20. G. Gholamibozanjani, M. Farid, Application of an active PCM storage system into a building for heating/cooling load reduction. Energy. 210, 118572 (2020).

21. A. de Gracia, Dynamic building envelope with PCM for cooling purposes - Proof of concept. Appl. Energy. 235, 1245-1253 (2019).

22. IMD New Delhi, SFD current month extremes. accesed 2021-11-15 (2021), (available at https://amssdelhi.gov.in/).

23. F. Kuznik, J. Virgone, Experimental assessment of a phase change material for wall building use. Appl. Energy. 86, 2038-2046 (2009).

24. S. Gobinath, G. Senthilkumar, N. Beemkumar, Comparative study of room temperature control in buildings with and without the use of PCM in walls. Energy Sources, Part A Recover. Util. Environ. Eff. 40, 1765-1771 (2018).

25. A. M. Morsy, M. T. Barako, V. Jankovic, V. D. Wheeler, M. W. Knight, G. T. Papadakis, L. A. Sweatlock, P. W. C. Hon, M. L. Povinelli, Experimental demonstration of dynamic thermal regulation using vanadium dioxide thin films. Sci. Rep. 10, 1-10 (2020).

26. A. Seeboth, R. Ruhmann, O. Mühling, Thermotropic and thermochromic polymer based materials for adaptive solar control. Materials (Basel). 3, 5143-5168 (2010).

27. Z. Li, W. Chen, Progress in dynamic emissivity regulation: control methods, material systems, and applications. Mater. Chem. Front. 5, 6315-6332 (2021).

28. O. Roubeau, Triazole-based one-dimensional spin-crossover coordination polymers. Chem. - A Eur. J. 18, 15230-15244 (2012).

29. K. Senthil Kumar, M. Ruben, Emerging trends in spin crossover (SCO) based functional materials and devices. Coord. Chem. Rev. 346, 176-205 (2017).

30. F. Bigdeli, C. T. Lollar, A. Morsali, H. C. Zhou, Switching in Metal-Organic Frameworks. Angew. Chemie - Int. Ed. 59, 4652-4669 (2020).

31. Y. S. Koo, J. R. Galán-Mascarós, Spin crossover probes confer multistability to organic conducting polymers. Adv. Mater. 26, 6785-6789 (2014).

32. E. Coronado, J. R. Galán-Mascarós, M. Monrabal-Capilla, J. García-Martínez, P. PardoIbáñez, Bistable spin-crossover nanoparticles showing magnetic thermal hysteresis near room temperature. Adv. Mater. 19, 1359-1361 (2007).

33. A. Bousseksou, G. Molnár, L. Salmon, W. Nicolazzi, Molecular spin crossover phenomenon: Recent achievements and prospects. Chem. Soc. Rev. 40, 3313-3335 (2011).

34. M. D. Manrique-Juarez, F. Mathieu, V. Shalabaeva, J. Cacheux, S. Rat, L. Nicu, T. Leïchlé, L. Salmon, G. Molnár, A. Bousseksou, A Bistable Microelectromechanical System Actuated by Spin-Crossover Molecules. Angew. Chemie - Int. Ed. 56, 8074-8078 (2017).

35. M. A. Halcrow, Structure:function relationships in molecular spin-crossover complexes. Chem. Soc. Rev. 40, 4119-4142 (2011).

36. L. Zhu, A. Raman, S. Fan, Color-preserving daytime radiative cooling. Appl. Phys. Lett. 
103, 223902 (2013).

37. W. Zhang, C. Wang, K. Chen, Y. Yin, Raspberry-Shaped Thermochromic Energy Storage Nanocapsule with Tunable Sunlight Absorption Based on Color Change for Temperature Regulation. Small. 15, 1903750 (2019).

38. P. J. Von Ranke, B. P. Alho, R. M. Ribas, E. P. Nobrega, A. Caldas, V. S. R. De Sousa, M. V. Colaço, L. F. Marques, D. L. Rocco, P. O. Ribeiro, Colossal refrigerant capacity in [Fe(hyptrz)3] A2 - H2 O around the freezing temperature of water. Phys. Rev. B. 98 (2018).

39. S. P. Vallone, A. N. Tantillo, A. M. dos Santos, J. J. Molaison, R. Kulmaczewski, A. Chapoy, P. Ahmadi, M. A. Halcrow, K. G. Sandeman, Giant Barocaloric Effect at the Spin Crossover Transition of a Molecular Crystal. Adv. Mater. 31 (2019).

40. M. Romanini, Y. X. Wang, K. Gürpinar, G. Ornelas, P. Lloveras, Y. Zhang, W. Zheng, M. Barrio, A. Aznar, A. Gràcia-Condal, B. Emre, O. Atakol, C. Popescu, H. Zhang, Y. Long, L. Balicas, J. Lluís Tamarit, A. Planes, M. Shatruk, L. Mañosa, Giant and Reversible Barocaloric Effect in Trinuclear Spin-Crossover Complex Fe3(bntrz)6(tcnset)6. Adv. Mater. 33, 2008076 (2021).

41. K. Ridier, Y. Zhang, M. Piedrahita-Bello, C. M. Quintero, L. Salmon, G. Molnár, C. Bergaud, A. Bousseksou, Heat Capacity and Thermal Damping Properties of SpinCrossover Molecules: A New Look at an Old Topic. Adv. Mater. 32 (2020).

42. A. Bousseksou, L. Salmon, G. Molnár, C. Bergaud, K. Ridier, C. Quintero, WO2021064094A1 (2020), (available at https://patents.google.com/patent/WO2021064094A1/en).

43. C. Ferlay, O. Ceysson, EP3095831A1 (2016), (available at https://patents.google.com/patent/EP3095831A1/fr).

44. A. Tokarev, L. Salmon, Y. Guari, W. Nicolazzi, G. Molnár, A. Bousseksou, Cooperative spin crossover phenomena in [Fe(NH2trz)3](tosylate)2 nanoparticles. Chem. Commun. 46, 8011-8013 (2010).

45. J. A. Real, A. B. Gaspar, M. C. Muñoz, Thermal, pressure and light switchable spincrossover materials. Dalt. Trans., 2062-2079 (2005).

46. C. Etrillard, V. Faramarzi, J.-F. Dayen, J.-F. Letard, B. Doudin, Photoconduction in $\left[\mathrm{Fe}(\mathrm{Htrz})_{2}(\operatorname{trz})\right]\left(\mathrm{BF}_{4}\right) \cdot \mathrm{H}_{2} \mathrm{O}$ nanocrystals. Chem. Commun. 47, 9663 (2011).

47. A. Sousaraei, C. Queirós, F. G. Moscoso, T. Lopes-Costa, J. M. Pedrosa, A. M. G. Silva, L. Cunha-Silva, J. Cabanillas-Gonzalez, Subppm Amine Detection via Absorption and Luminescence Turn-On Caused by Ligand Exchange in Metal Organic Frameworks. Anal. Chem. 91, 15853-15859 (2019).

48. I. A. Gural'Skiy, C. M. Quintero, J. Sanchez Costa, P. Demont, G. Molnár, L. Salmon, H. J. Shepherd, A. Bousseksou, Spin crossover composite materials for electrothermomechanical actuators. J. Mater. Chem. C. 2, 2949-2955 (2014).

49. K. Ridier, A. C. Bas, Y. Zhang, L. Routaboul, L. Salmon, G. Molnár, C. Bergaud, A. Bousseksou, Unprecedented switching endurance affords for high-resolution surface temperature mapping using a spin-crossover film. Nat. Commun. 11, 3611 (2020).

50. A. Grosjean, P. Négrier, P. Bordet, C. Etrillard, D. Mondieig, S. Pechev, E. Lebraud, J. F. 
Létard, P. Guionneau, Crystal structures and spin crossover in the polymeric material $\left[\mathrm{Fe}(\mathrm{Htrz})_{2}(\mathrm{trz})\right]\left(\mathrm{BF}_{4}\right)$ including coherent-domain size reduction effects. Eur. J. Inorg. Chem. 2, 796-802 (2013).

51. J. Kröber, J.-P. Audière, R. Claude, E. Codjovi, O. Kahn, J. G. Haasnoot, F. Grolière, C. Jay, B. Azzedine, J. Linarès, F. Varret, G. V. Anne, Spin Transitions and Thermal Hysteresis in the Molecular-Based Materials $\left[\mathrm{Fe}(\mathrm{Htrz})_{2}(\operatorname{trz})\right]\left(\mathrm{BF}_{4}\right)$ and $\left[\mathrm{Fe}(\mathrm{Htrz})_{3}\right]\left(\mathrm{BF}_{4}\right)_{2} \cdot \mathrm{H}_{2} \mathrm{O}(\mathrm{Htrz}=1,2,4-4 \mathrm{H}$-triazole; trz $=1,2,4$-triazolato $)$. Chem. Mater. 6, 1404-1412 (1994).

Acknowledgments: We thanks Hector Guerrero for his very valuable expertise and criticisms. JSC thanks funds from the Spanish MINECO through National Research Project (CTQ201680635-P), the Spanish MICIU (C AIRE PID2019-111479GB-I00) the Ramon y Cajal Research program (RYC-2014-16866), the Comunidad de Madrid (PEJD-2017-PRE/IND-4037) and the NANOMAGCOST (P2018/NMT-4321). IMDEA Nanociencia acknowledges support from the 'Severo Ochoa' Programme for Centres of Excellence in R\&D (MINECO, Grant SEV-2016-0686). MAG thanks the Spanish Ministerio de Ciencia e Innovación (PID2020-114192RB-C41). AE thanks the Comunidad de Madrid I+D+i grant program (Atracción de Talento project 2018T1/IND-1005) and the AECC project Ideas Semilla 2019.

\section{Conflicts of interest}

There are no conflicts to declare. 


\section{Supplementary Information}

\section{Passive control of temperature fluctuations through a sunlight-induced spin transition in a molecular material}

Esther Resines-Urien, ${ }^{1}$ Miguel Ángel García García-Tuñon, ${ }^{2}$ Mar Garcia-Hernandez, ${ }^{3}$ J. Alberto RodríguezVelamazán, ${ }^{4}$ Ana Espinosa, ${ }^{1 *}$ Jose Sanchez Costa ${ }^{1 *}$ ana.espinosa@imdea.org; jose.sanchezcosta@imdea.org

1) Experimental Section

2) Synthesis of 1-3 and 1@PMMA-3@PMMA

3) Polymeric structure

4) Pictures of 1-3

5) Optical reflectivity measurements

6) Magnetic characterization

7) Thermocromic reversibility

8) FTIR

9) Powder X-ray Diffraction (PXRD) study

10) Thermogravimetric analyses

11) Absorption spectra

12) Setup images

\section{1) Experimental Section}

Materials. Chemicals and reagents were purchased from commercial suppliers and used as received.

Physical measurements.

- Optical reflectivity measurements were performed using a MOTIC SMZ-171 optical stereoscope coupled with a MOTICAM 3. Images were collected in BMP format without any filter using the Motic Images Plus 3.0 software, with the mean value from each region of interest (ROI) analyzed under the ImageJ program. The temperature was controlled using a Linkam T95 system controller and a LNP 95 Liquid Nitrogen Cooling System.

- TGA was performed using a TA Instrument TGAQ500 with a ramp of $2{ }^{\circ} \mathrm{C} \min ^{-1}$ under air from 30 to $600^{\circ} \mathrm{C}$.

- FT-IR spectra were recorded as neat samples in the range $400-4000 \mathrm{~cm}^{-1}$ on a Bruker Tensor 27 (ATR device) Spectrometer.

- Elemental analyses (C, H and N) were performed on a LECO CHNS-932 Analyzer at the "Servicio Interdepartamental de Investigación (SIdI)" at Autónoma University of Madrid.

- Magnetic susceptibility measurements were carried out in a Quantum Design MPMS-5S SQUID magnetometer under a 10000 Oe field at a rate of $1^{\circ} \mathrm{C} \cdot \mathrm{min}^{-1}$. Each sample was 
secured inside a plastic capsule. Pascal constants were used to correct for the diamagnetic contribution.

- Powder X ray diffraction data was collected in a Rigaku Smartlab SE diffractometer with a Bragg-Brentano configuration, using $\mathrm{Cu}-\mathrm{K} \alpha$ radiation $(\lambda=0.1541 \mathrm{~nm})$. The samples were measured between 5 and $50^{\circ}$ with a speed of $1.8^{\circ} \mathrm{min}^{-1}$ under an X-Ray fluorescence reduction mode, at room temperature.

- The absorption spectra were measured with a CCS200 - Compact Spectrometer between $1000-400 \mathrm{~cm}^{-1}$. The temperature dependence experiments were performed using the Linkam T95 system controller and a LNP 95 Liquid Nitrogen Cooling System.

- The thermo-optic analyses were performed using a VeraSol LED solar simulator (Newport) producing 1 sun AM $1 \mathrm{G}\left(1000 \mathrm{~W} \cdot \mathrm{m}^{-2}\right)$ simulated sunlight.

- The thermal images were acquired with a real-time infrared camera FLIR T540 (FLIR Ltd, USA). 


\section{Synthesis of 1-3 and 1@PMMA-3@PMMA}

\section{Synthesis of 1,2 and 3}

Compound 1 was synthetized at room temperature, by adding drop by drop a solution of $0.59 \mathrm{mmol}$ of $\mathrm{NH}_{2} \operatorname{trz}\left(\mathrm{NH}_{2}\right.$ trz $=4$-Amino-4H-1,2,4-triazole $)$ in $3 \mathrm{~mL}$ of ethanol on top of a solution of $0.20 \mathrm{mmol}$ of $\mathrm{Fe}(\mathrm{OTs})_{2}(\mathrm{OTs}=$ tosylate) in $3 \mathrm{~mL}$ of distilled water. The solution was stirred for 1 hour, filtered and washed with ethanol. 1 was obtained as a pink powder in $87 \%$ yield. $25.79 \%$.

Anal. calcd for $1 \cdot 0.4 \mathrm{H}_{2} \mathrm{O}$ : C $36.53 \%, \mathrm{H} 4.11 \%, \mathrm{~N} 25.56 \%$; found $\mathrm{C} 36.34 \%, \mathrm{H} 4.05 \%$, N

FTIR $1\left(\mathrm{~cm}^{-1}\right): v=3441(\mathrm{w} ; v(\mathrm{OH})), 3293(\mathrm{~m} ; v(\mathrm{NH})), 3210(\mathrm{w}), 3062(\mathrm{~m} ; v(\mathrm{CH}) \mathrm{ar}), 3012$ $(\mathrm{w}), 2924(\mathrm{w}), 1631(\mathrm{~m}), 1600(\mathrm{w}), 1546(\mathrm{~m} ; \delta(\mathrm{NH})), 1496(\mathrm{w}), 1449(\mathrm{w} ; \delta(\mathrm{CH}) \mathrm{ar}), 1396(\mathrm{w})$, $1170\left(\mathrm{~s} ; v(\mathrm{~S}=\mathrm{O})_{\text {OTs }}\right), 1122(\mathrm{~s}), 1098(\mathrm{~m}), 1033\left(\mathrm{~s} ; v(\mathrm{~S}=\mathrm{O})_{\mathrm{OTs}}\right), 1008\left(\mathrm{~s} ; v(\mathrm{~S}=\mathrm{O})_{\mathrm{OTs}}\right), 908(\mathrm{w}), 881$ $(\mathrm{w}), 813\left(\mathrm{~m} ; \delta(\right.$ ring) $), 709(\mathrm{w}), 681\left(\mathrm{~s} ; v(\mathrm{CS})_{\mathrm{OTs}}\right), 623(\mathrm{~s}), 563\left(\mathrm{~s} ; v(\mathrm{CS})_{\mathrm{OTs}}\right), 493(\mathrm{w}), 457(\mathrm{w})$.

Compound 2 was synthetized at room temperature, dissolving $1 \mathrm{mmol}$ of $\mathrm{Fe}\left(\mathrm{BF}_{4}\right)_{2} \cdot 6 \mathrm{H}_{2} \mathrm{O}$ in $3 \mathrm{ml}$ of distilled water and adding it drop by drop to a solution of $3 \mathrm{mmol}$ of Htrz (Htrz $=1,2,4-$ triazole) in $3 \mathrm{~mL}$ of ethanol. The resulting solution was stirred for 24 hours, filtered and washed with ethanol obtaining 2 as a pink powder (76\% yield).

Anal. calcd for 2·1.35 $\mathrm{H}_{2} \mathrm{O}$ : C 19.31, H 2.89, N 33.78; found C 19.07, H 2.66, N 33.79.

FTIR $2\left(\mathrm{~cm}^{-1}\right): v=3170(\mathrm{w} ; v(\mathrm{NH})), 3093(\mathrm{w} ; v(\mathrm{CH})$ ar $), 3008(\mathrm{w}), 2915(\mathrm{w}), 2845(\mathrm{w}), 2698$ $(\mathrm{w}), 2621(\mathrm{w}), 2535(\mathrm{w}), 2535(\mathrm{w}), 2457(\mathrm{w}), 1749(\mathrm{w}), 1719(\mathrm{w}), 1639(\mathrm{w}), 1535(\mathrm{~m} ; \delta(\mathrm{NH}))$, $1495(\mathrm{~m}), 1453(\mathrm{~m} ; \delta(\mathrm{CH}) \mathrm{ar}), 1309(\mathrm{~m}), 1285(\mathrm{~m}), 1220(\mathrm{w}), 1190(\mathrm{w}), 1163(\mathrm{~m}), 1144(\mathrm{~m}), 1063$ $\left(\mathrm{s} ; v(\mathrm{BF})_{\mathrm{BF} 4}\right), 1034\left(\mathrm{~s} ; v(\mathrm{BF})_{\mathrm{BF} 4}\right), 977(\mathrm{~m}), 912(\mathrm{w}), 866(\mathrm{~m}), 827(\mathrm{w}), 765(\mathrm{w}), 679(\mathrm{~m}), 631(\mathrm{~s})$, $523(\mathrm{~m}), 468(\mathrm{w}), 437(\mathrm{w})$.

Compound 3 was synthetized by adding drop by drop a solution of $3 \mathrm{mmol}$ of $\mathrm{NH}_{2}$ trz $\left(\mathrm{NH}_{2}\right.$ trz $=4$-Amino-4H-1,2,4-triazole $)$ in $3 \mathrm{~mL}$ of ethanol on top of a solution of $1 \mathrm{mmol}$ of $\mathrm{Zn}\left(\mathrm{NO}_{3}\right)_{2}$ in $3 \mathrm{~mL}$ of distilled water. The solution was stirred for 1 hour, and the white precipitate was filtered and washed with ethanol. 3 was obtained as a white powder ( $85 \%$ yield).

Anal. calcd for 3 $1 \mathrm{H}_{2} \mathrm{O}$ : C 15.68, $\mathrm{H}$ 3.07, N 42.66; found $\mathrm{C} 15.33, \mathrm{H} 3.14, \mathrm{~N} 43.01$.

FTIR $3\left(\mathrm{~cm}^{-1}\right): v=3520(\mathrm{w}), 3319(\mathrm{~m} ; v(\mathrm{NH})), 3218(\mathrm{w}), 3070\left(\mathrm{~m} ; v(\mathrm{CH})_{\mathrm{ar}}\right), 3004(\mathrm{w})$, $1753(\mathrm{w}), 1632\left(\mathrm{~m} ; v(\mathrm{NO})_{\mathrm{as}, \mathrm{NO} 3}\right), 1547(\mathrm{~m} ; \delta(\mathrm{NH})), 1485\left(\mathrm{w} ; \delta(\mathrm{CH})_{\mathrm{ar}}\right), 1339\left(\mathrm{~s} ; v(\mathrm{NO})_{\mathrm{sim}, \mathrm{NO} 3}\right)$, $1219(\mathrm{~m}), 1088(\mathrm{~m}), 1030(\mathrm{~m}), 996(\mathrm{~m}), 904(\mathrm{w}), 828$ (m; v(NO)trans/cis,NO3), $712(\mathrm{w}), 690(\mathrm{w})$, $622(\mathrm{~s}), 421(\mathrm{w})$.

\section{Synthesis of 1@PMMA, 2@PMMA and 3@PMMA}

The 1@PMMA, 2@PMMA and 3@PMMA films (3\% w/w) were prepared by mixing 0.2 $\mathrm{g}$ of the respective sample powder with $1.98 \mathrm{~g}$ of PMMA (PMMA = poly(methyl methacrylate; average $\left.\mathrm{M}_{\mathrm{w}} \sim 120,000 \mathrm{~g} \cdot \mathrm{mol}^{-1}\right)$. This mixture was dissolved in $\mathrm{CHCl}_{3}$, sonicated for 30 minutes and deposited in a mold $(5 \mathrm{~cm} \times 5 \mathrm{~cm})$, that was placed in the fridge overnight so the $\mathrm{CHCl}_{3}$ evaporates slowly and no bubbles appear. The composite was then carefully extracted from the mold.

FTIR 1@PMMA $\left(\mathrm{cm}^{-1}\right): v=3290(\mathrm{w} ; v(\mathrm{NH})), 3110(\mathrm{w} ; v(\mathrm{CH}) \mathrm{ar}), 2995(\mathrm{w} ;$ PMMA $), 2950$ (m; PMMA), 2851 (w), 1724 (s; PMMA), $1614(\mathrm{w}), 1546(\mathrm{w} ; \delta(\mathrm{NH})), 1480(\mathrm{w} ; \mathrm{PMMA}), 1446$ (w; PMMA), 1435 (m), 1386 (w; PMMA), 1269 (w; PMMA), 1239 (w; PMMA), 1189 (w; PMMA), 1169 (w; v(S=O) OTs), 1146 (s; PMMA), 1122 (s), $1098(\mathrm{w}), 1033$ (m; v(S=O) OTs), 1009 (m; $\left.v(\mathrm{~S}=\mathrm{O})_{\mathrm{OTs}}\right), 988$ (w; PMMA), 966 (w; PMMA), 912 (w; PMMA), 880 (w), 841 (w; PMMA), 812 (m; $\delta$ (ring), 749 (s; PMMA), 683 (s; v(CS) отs), 625 (s), 563 (s; v(CS)оTs), 481 (w; PMMA).

FTIR 2@PMMA $\left(\mathrm{cm}^{-1}\right): v=3170(\mathrm{~m} ; v(\mathrm{NH})), 3095\left(\mathrm{w} ; v(\mathrm{CH})_{\mathrm{ar}}\right), 3006(\mathrm{~m}), 2915(\mathrm{~m})$, 2848 (m), 2748 (w), 2698 (w), 2622 (w), 2536 (w), 1728 (m; PMMA), 1644 (w), 1536 (m; 
$\delta(\mathrm{NH})), 1496(\mathrm{~m}), 1453(\mathrm{~m}), 1388(\mathrm{w}), 1309(\mathrm{~m}), 1284(\mathrm{w}), 1221$ (w; PMMA), $1190(\mathrm{w}$;

PMMA), $1162(\mathrm{~m}), 1144(\mathrm{~m}), 1109(\mathrm{w}), 1063$ (s; $\left.v(\mathrm{BF})_{\mathrm{BF} 4)}\right) 1034\left(\mathrm{~s} ; v(\mathrm{BF})_{\mathrm{BF} 4}\right), 977(\mathrm{~m}), 912$ (w), 866 (m), 826 (w; PMMA), 764 (s; PMMA), 679 (m), 631 (s), 524 (m), 482 (w; PMMA), $471(\mathrm{w}), 437(\mathrm{w})$.

It should be noted that at temperatures above $125^{\circ} \mathrm{C}$ the PMMA starts degrading, so 2@PMMA, which undergoes the spin transition at higher temperatures, could not be characterized in HS by SQUID and only partially by optical reflectivity. FTIR 3@PMMA (cm$\left.{ }^{1}\right): v=3321(\mathrm{w} ; v(\mathrm{NH})), 3219(\mathrm{w}), 3070(\mathrm{w} ; v(\mathrm{CH}) \mathrm{ar}), 2998(\mathrm{~m} ; \mathrm{PMMA}), 2950$ (m; PMMA), $2844(\mathrm{w}), 1721$ (s; PMMA), $1635\left(\mathrm{w} ; v(\mathrm{NO})_{\mathrm{as}, \mathrm{NO} 3),} 1547(\mathrm{w} ; \delta(\mathrm{NH})), 1481(\mathrm{w} ; \mathrm{PMMA}), 1434\right.$

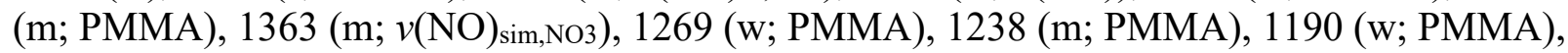
1143 (s; PMMA), 1088 (m), 1062 (w; PMMA), 1029 (w), 993 (m), 968 (w; PMMA), 913 (w), 842 (w; PMMA), 828 (w; v(NO)trans/cis,NO3), 748 (s; PMMA), 667 (m; PMMA), 623 (m), 554 (w; PMMA), 479 (w; PMMA), 458 (w).

\section{2) Polymeric structure}



Figure S1. Illustration of the 1D structure of 1. Compounds $\mathbf{2}$ and $\mathbf{3}$ present this same general backbone.

\section{3) Pictures of 1-3}

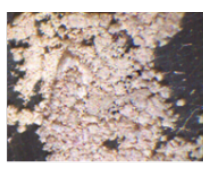

$\mathbf{1}_{\mathrm{HS}}$ $\left(50^{\circ} \mathrm{C}\right)$

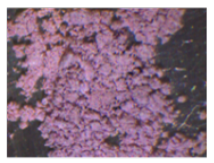

$\mathbf{1}_{\mathrm{LS}}$
$\left(-40^{\circ} \mathrm{C}\right)$

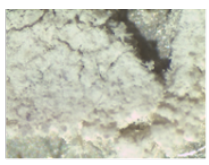

$\mathbf{2}_{\mathrm{HS}}$ $\left(120^{\circ} \mathrm{C}\right)$

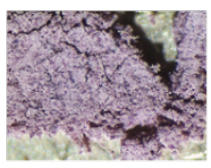

$\mathbf{2}_{\text {LS }}$



3

$\left(50^{\circ} \mathrm{C}\right)$

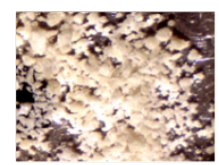

3

Figure S2. Pictures of 1-3 at the highest and lowest measured temperature, associated with the spin state.

\section{4) Optical reflectivity measurements}






Figure S3. Optical reflectivity measurements for 1-3 and 1@PMMA-3@PMMA.

\section{5) Magnetic characterization}

Compound 1 presents the HS state above RT, and changes abruptly to LS state upon cooling down. When the sample is heated, the HS state is recovered with a hysteresis of $14^{\circ} \mathrm{C}\left(\mathrm{T}_{1 / 2} \downarrow=12\right.$ ${ }^{\circ} \mathrm{C} ; \mathrm{T}_{1 / 2} \uparrow=26{ }^{\circ} \mathrm{C}$ ). The same type of behavior is observed for 1@PMMA although with a much more gradual transition (hysteresis $19^{\circ} \mathrm{C} ; \mathrm{T}_{1 / 2} \downarrow=-5^{\circ} \mathrm{C} ; \mathrm{T}_{1 / 2} \uparrow=14^{\circ} \mathrm{C}$ ). Compound 2 also exhibits a hysteretic SCO behavior between $70{ }^{\circ} \mathrm{C}$ and $103{ }^{\circ} \mathrm{C}$. This transition is shifted to even higher temperatures when combined with PMMA $\left(\mathrm{T}_{1 / 2} \downarrow=115^{\circ} \mathrm{C}\right)$. Naturally, neither compound $\mathbf{3}$ nor 3@PMMA display a spin transition, since $\mathrm{Zn}(\mathrm{II})$ is a $\mathrm{d}^{10}$ transition metal, and the possibility of SCO is nonexistent.

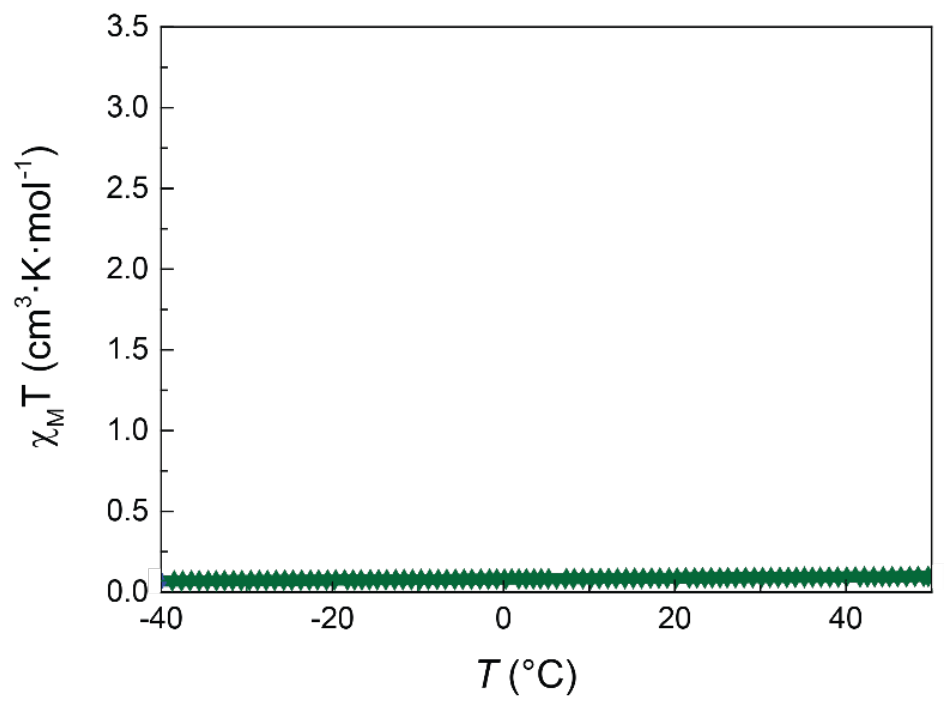

Figure S4. $\chi_{\mathrm{M}} T$ measured as a function of the temperature for PMMA. 


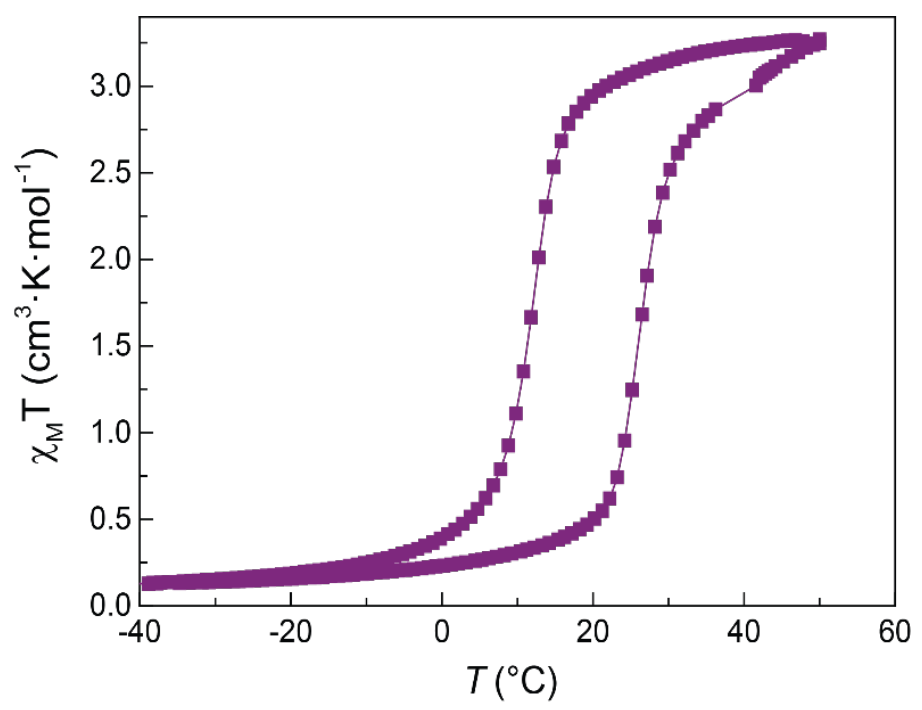

Figure S5. $\chi_{M} T$ measured as a function of the temperature for 1 .

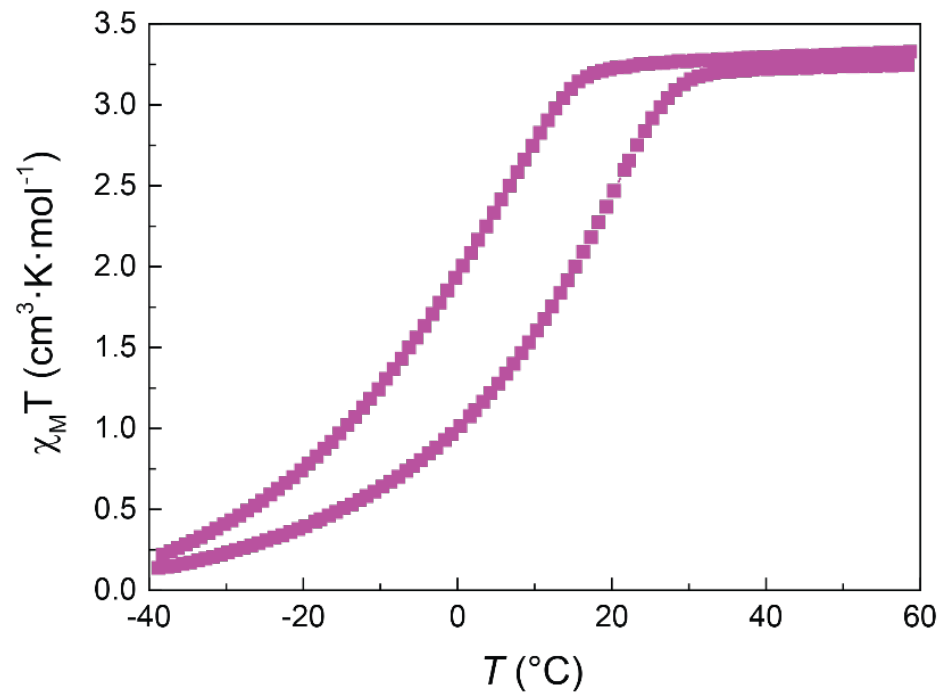

Figure S6. $\chi_{\mathrm{M}} T$ measured as a function of the temperature for 1@PMMA. 


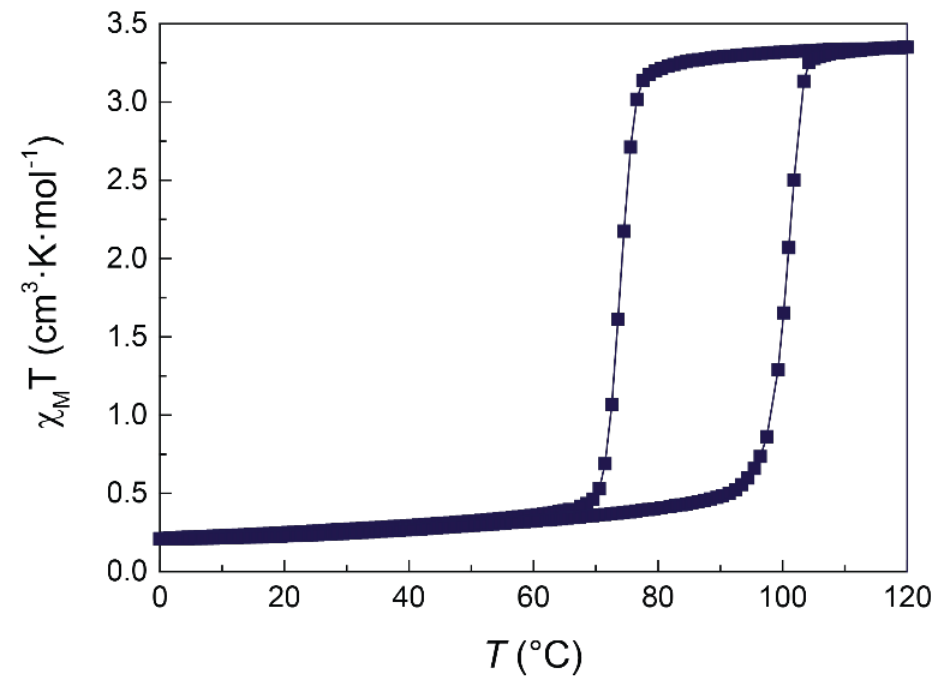

Figure S7. $\chi_{\mathrm{M}} T$ measured as a function of the temperature for 2 .

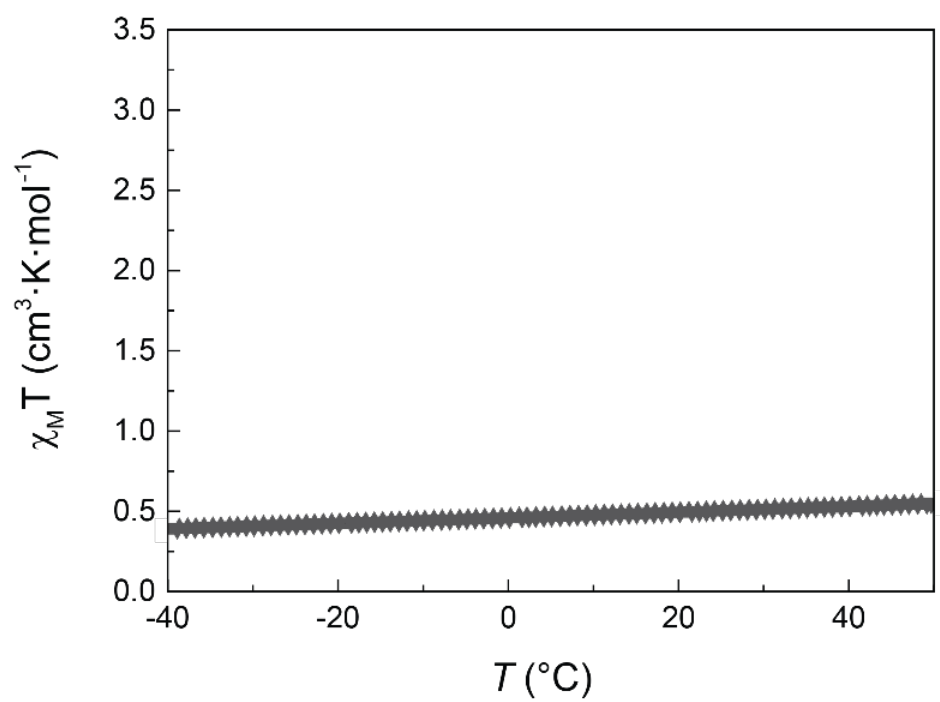

Figure S8. $\chi_{\mathrm{M}} T$ measured as a function of the temperature for 3 .

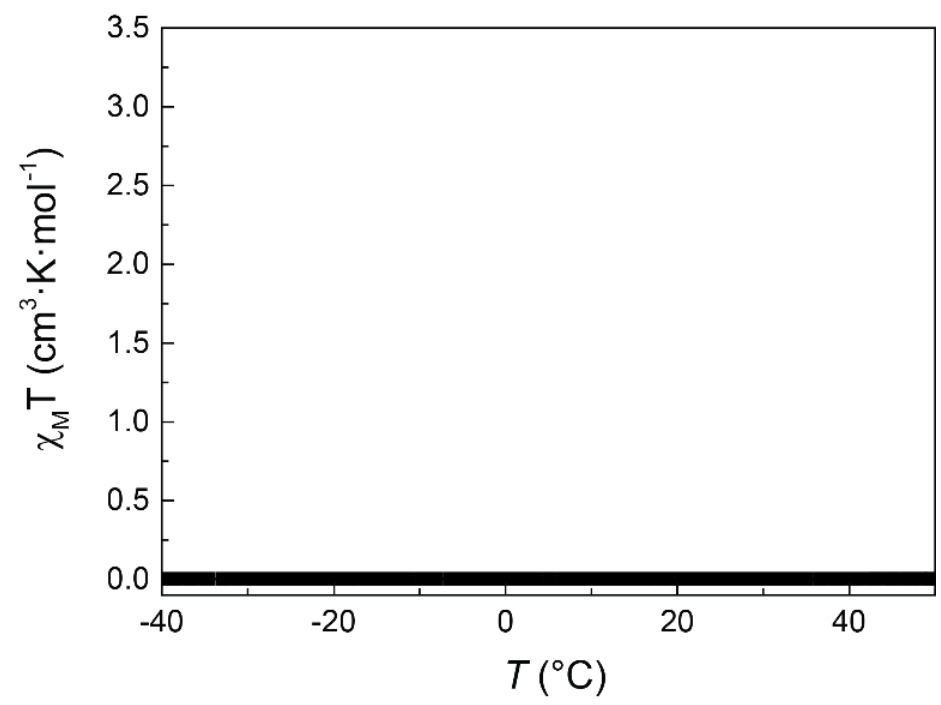


Figure 59. $\chi_{\mathrm{M}} T$ measured as a function of the temperature for 3@PMMA. 


\section{6) Thermocromic reversibility}

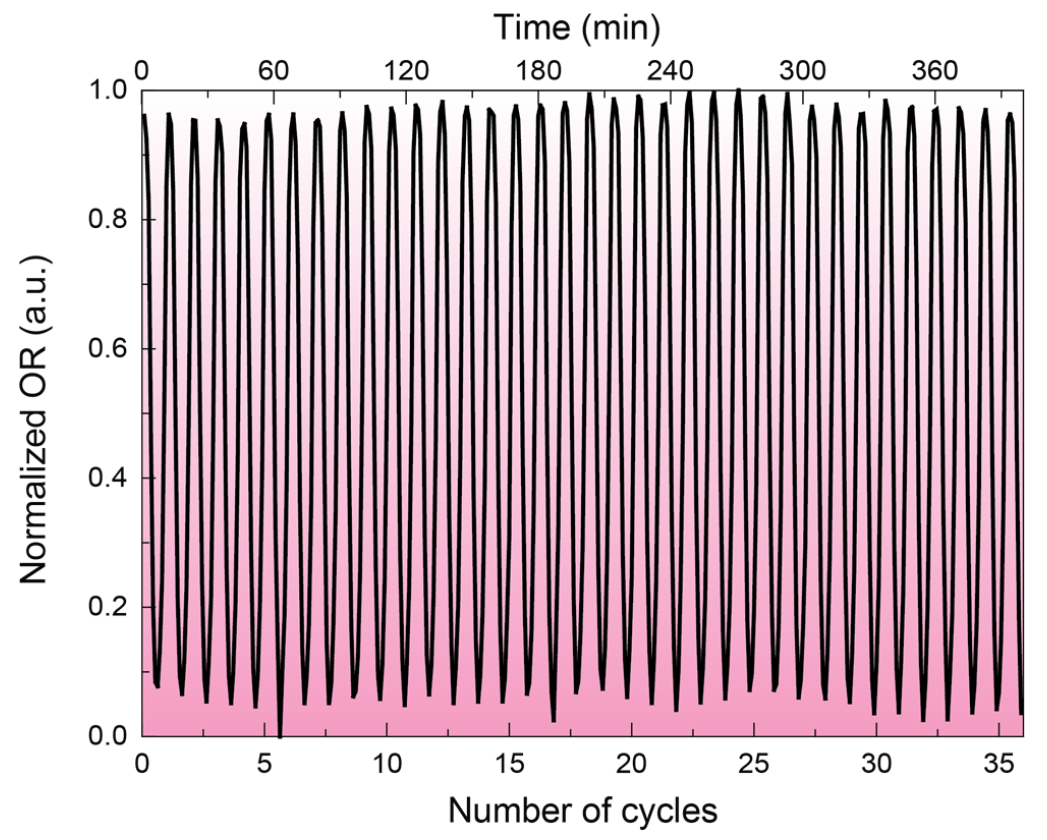

Figure S10. Thermochromic reversibility of 1@PMMA between $-50{ }^{\circ} \mathrm{C}$ and $60^{\circ} \mathrm{C}$. The color of the background is associated with the color of the composite: white at high temperatures (HS) and pink at low temperatures (LS).

\section{7) FTIR}

The distinctive signals from the coordination polymers and the ones from PMMA can be seen in the 1@PMMA-3@PMMA spectra by FTIR spectroscopy.

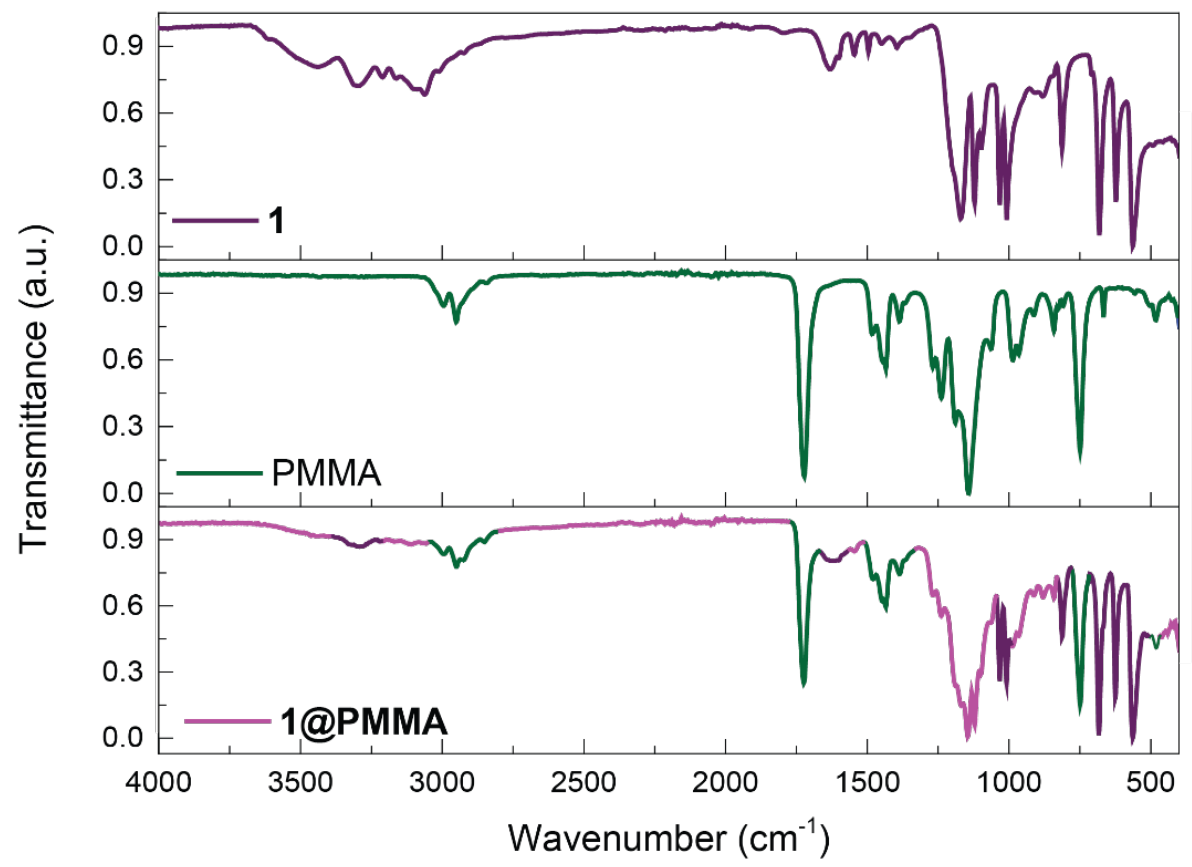


Figure S11. IR spectrum of 1, PMMA and 1@PMMA between $4000 \mathrm{~cm}^{-1}$ and $400 \mathrm{~cm}^{-}$ 1. For 1@PMMA the vibration bands that can be associated with compound $\mathbf{1}$ are represented in purple, while the ones coming from PMMA are colored in blue. The bands in pink are the result of the combination of $\mathbf{1}$ and PMMA signals.

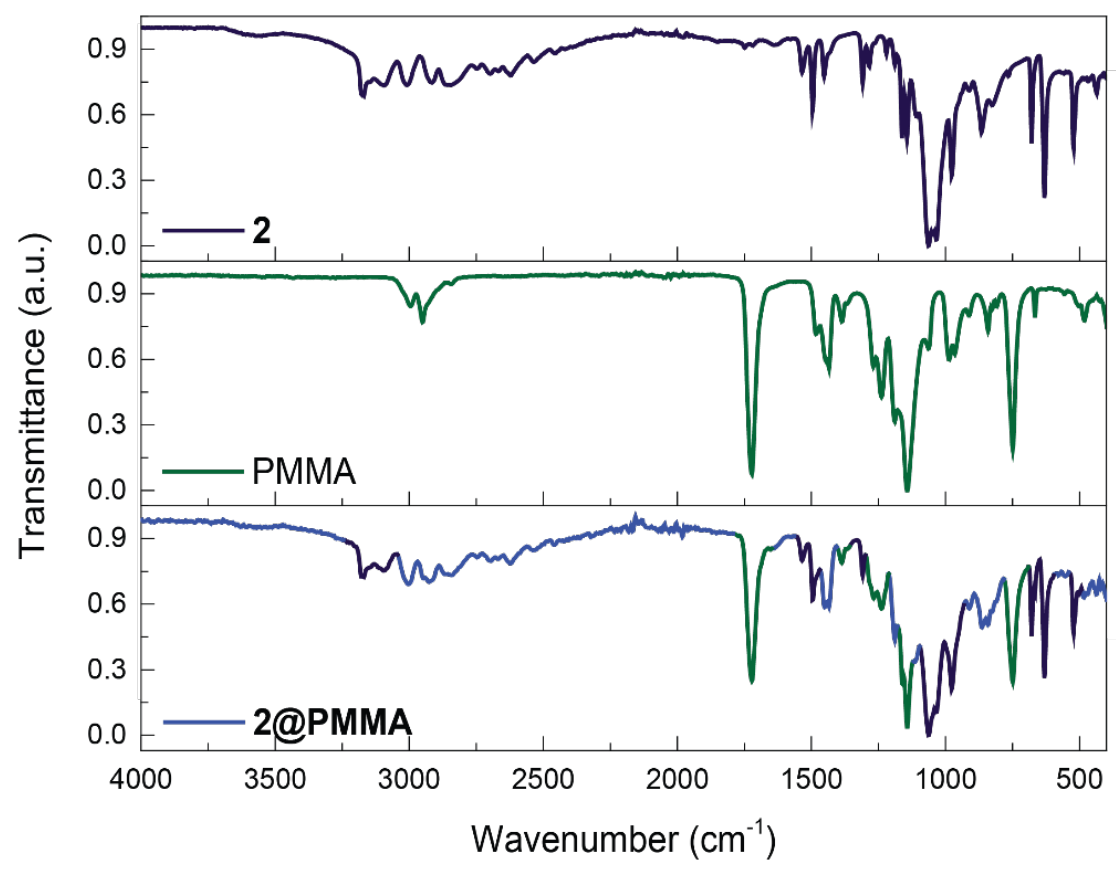

Figure S12. IR spectrum of 2, PMMA and 2@PMMA between $4000 \mathrm{~cm}^{-1}$ and 400 $\mathrm{cm}^{-1}$. In the case of $\mathbf{2} @$ PMMA the signals that can be attributed with $\mathbf{2}$ are depicted in brown, whereas those from PMMA are in blue. The black bands result from the combined signals of 2 and PMMA.




Figure S13. IR spectrum of 3, PMMA and 3@PMMA between $4000 \mathrm{~cm}^{-1}$ and $400 \mathrm{~cm}^{-}$ 1. In the spectrum of $3 @$ PMMA the signals attributable to 3 are shown in maroon, and those of PMMA are indicated in blue. The signals that arise from a combination of $\mathbf{3}$ and PMMA are in red.

\section{8) Powder X-ray Diffraction (PXRD) study}

Even though single crystals of 1-3 could not be obtained, the polycrystalline samples were measured by powder X-ray diffraction PXRD.

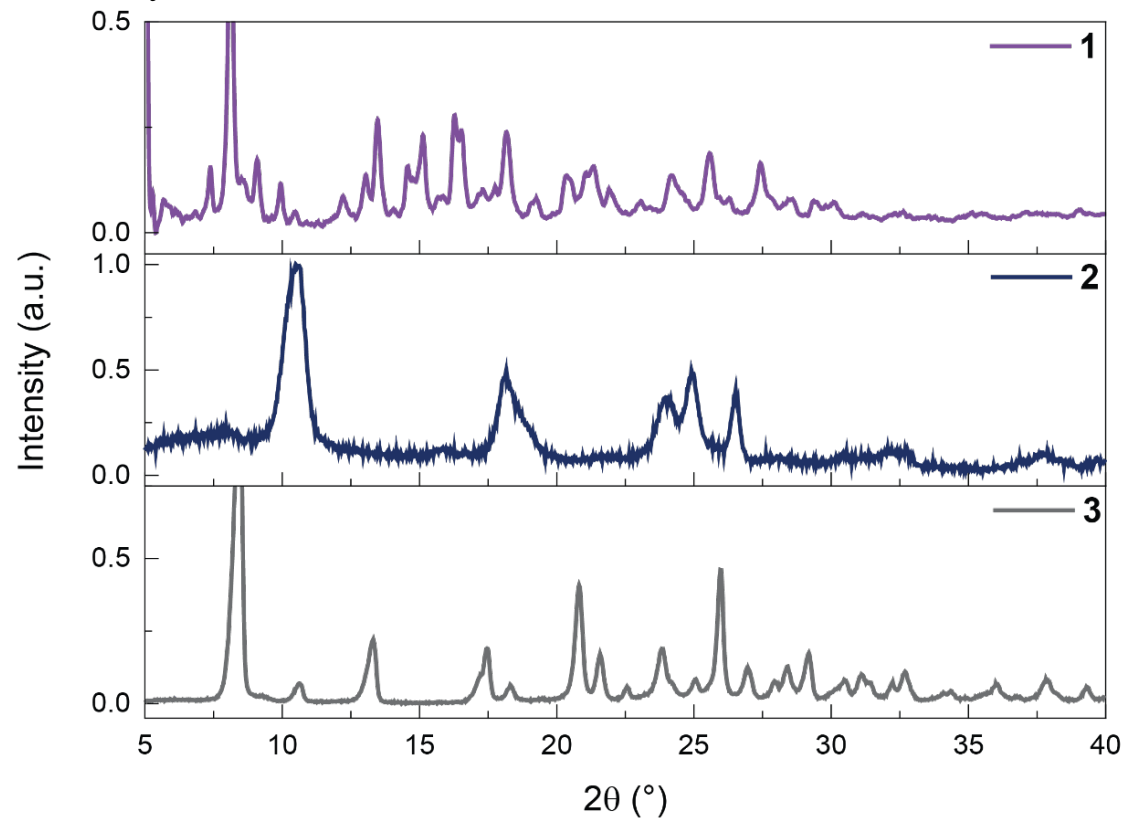

Figure S14. PXRD pattern of 1, 2 and 3.

\section{9) Thermogravimetric analyses}

The thermogravimetric analyses (TGA) also show that the profiles are different for 1-3. The profile of 1@PMMA-3@PMMA in the temperature range between $30{ }^{\circ} \mathrm{C}$ and $240{ }^{\circ} \mathrm{C}$ is consistent with that of PMMA, with a weight loss between $125{ }^{\circ} \mathrm{C}$ and $200{ }^{\circ} \mathrm{C}$. At temperatures higher than 240 ${ }^{\circ} \mathrm{C}$ the weight loss curve follows a similar pattern to that of the corresponding coordination polymer. Hence, 1@PMMA presents the most gradual weight loss above $240{ }^{\circ} \mathrm{C}$, and a slight plateau can be seen at $300{ }^{\circ} \mathrm{C}$, similarly to 1 . On the other hand, 2 and 2@PMMA exhibit a onestep abrupt weight loss. Compounds 3 and 3@PMMA display the most abrupt weight loss, and a plateau can be observed at $300{ }^{\circ} \mathrm{C}$ for 3 . While this plateau is not evident in 3@PMMA, a change in the slope appears at this temperature. 


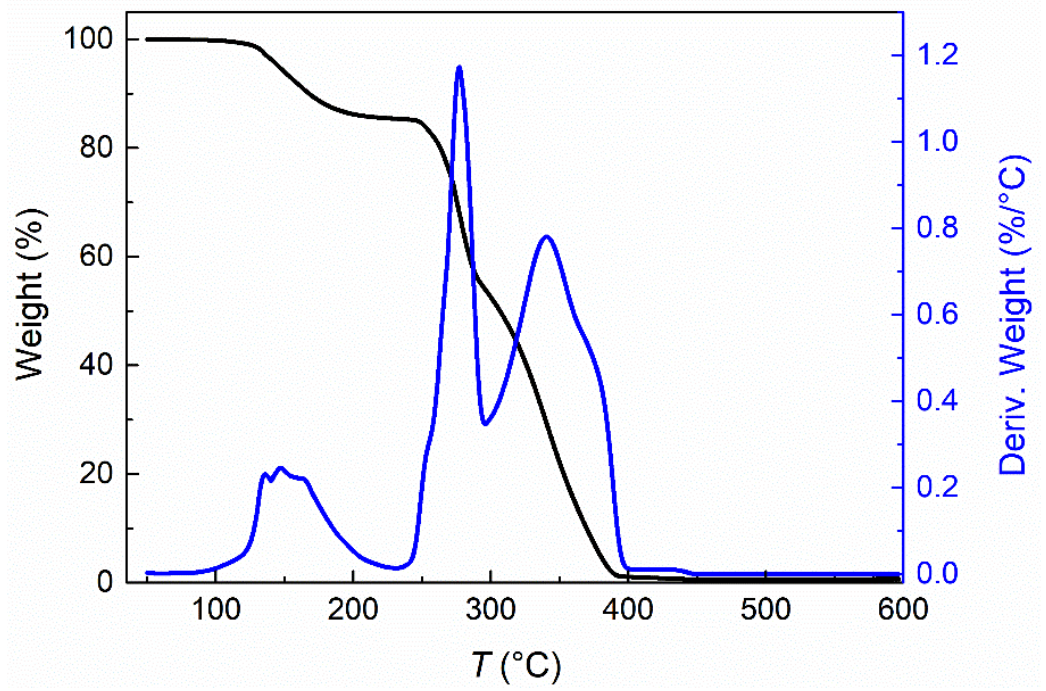

Figure S15. Thermogravimetric analysis of PMMA between $30^{\circ} \mathrm{C}$ and $600^{\circ} \mathrm{C}$.

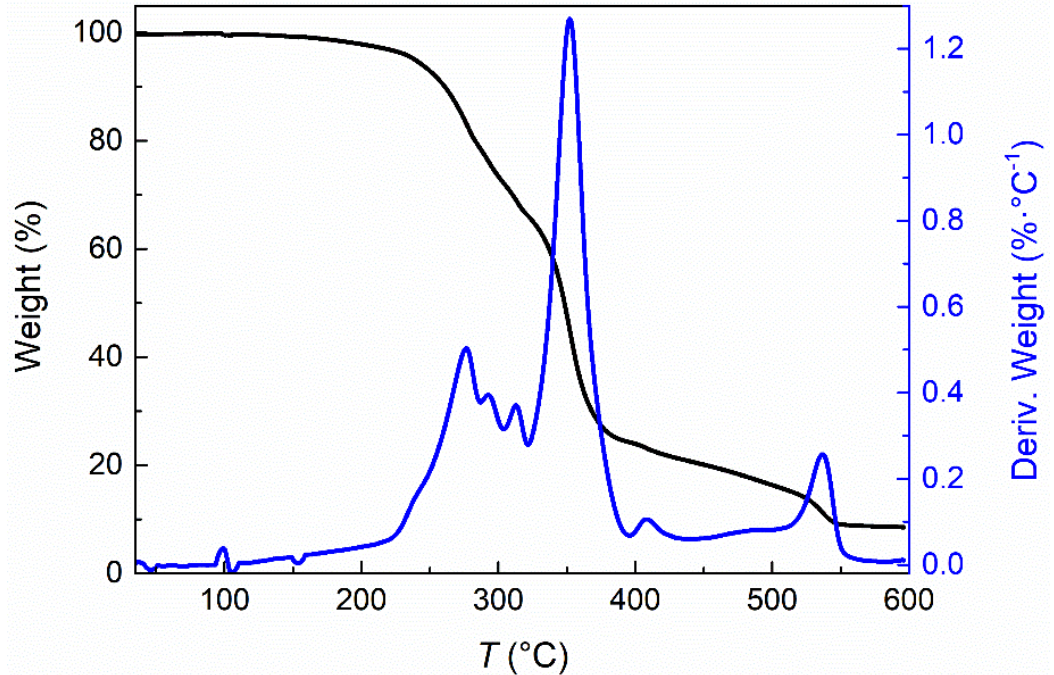

Figure S16. Thermogravimetric analysis of 1 between $30^{\circ} \mathrm{C}$ and $600^{\circ} \mathrm{C}$.

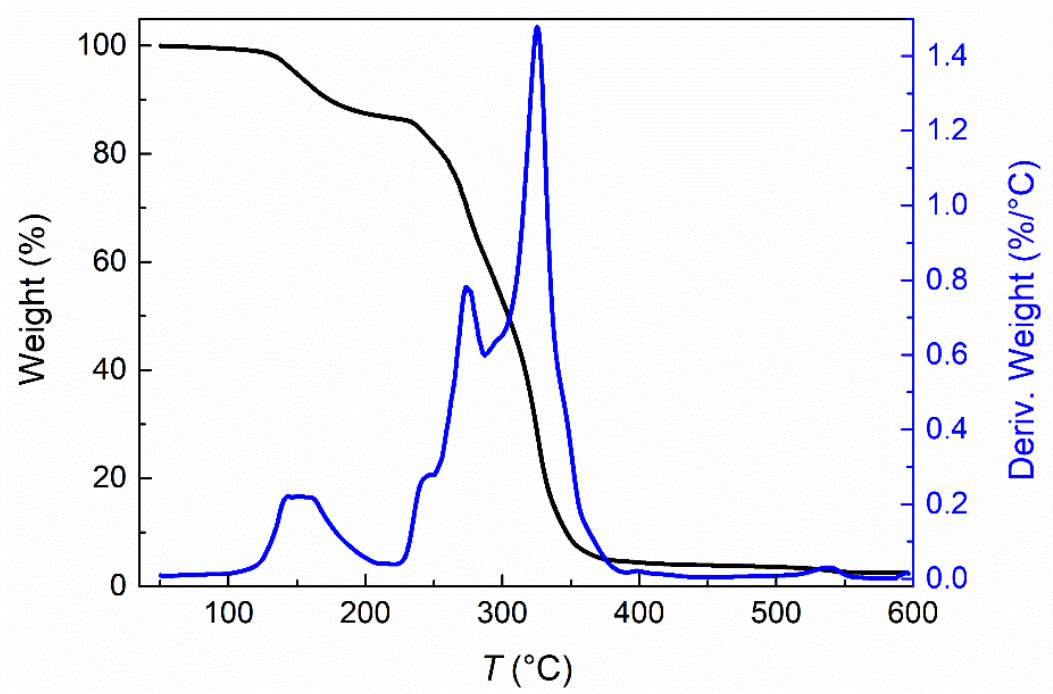


Figure S17. Thermogravimetric analysis of 1@PMMA between $30{ }^{\circ} \mathrm{C}$ and $600^{\circ} \mathrm{C}$.

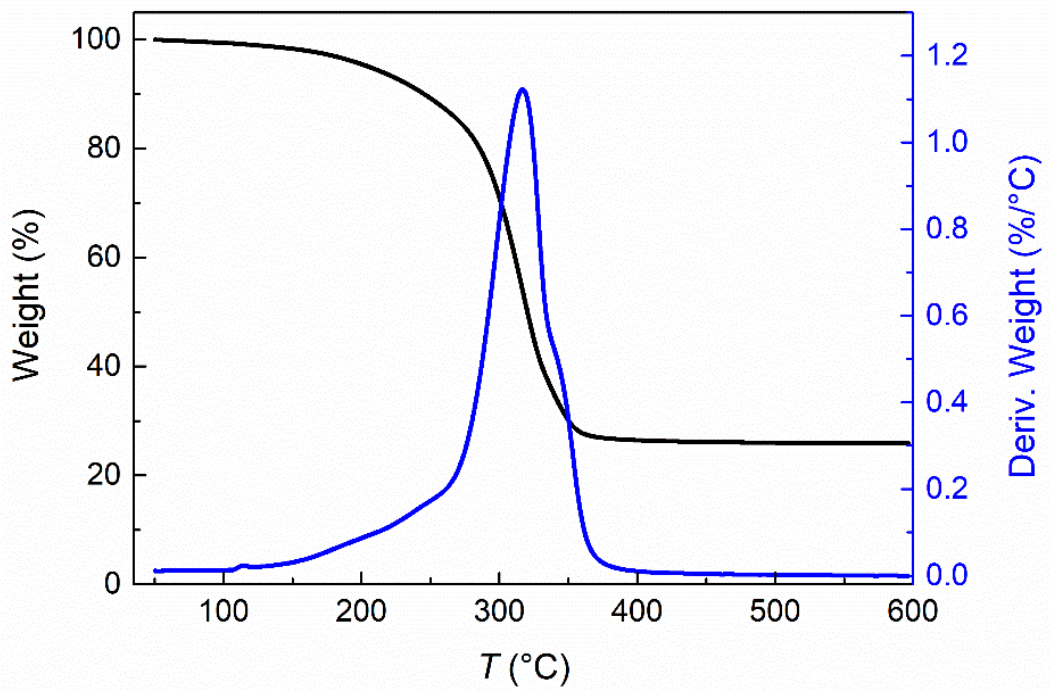

Figure S18. Thermogravimetric analysis of 2 between $30^{\circ} \mathrm{C}$ and $600^{\circ} \mathrm{C}$.

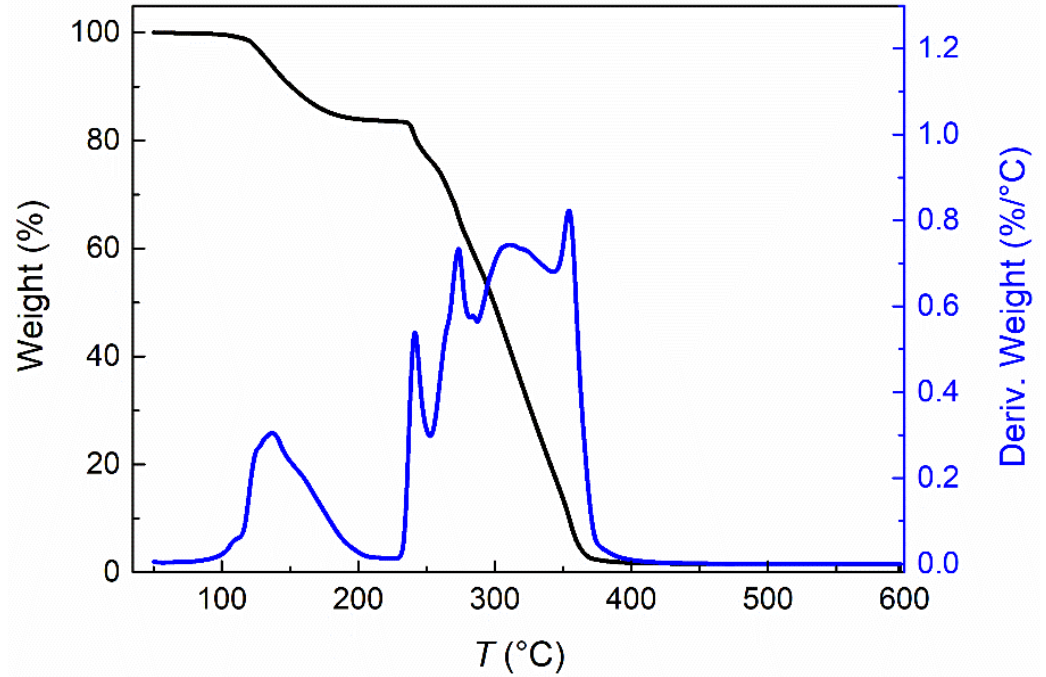

Figure S19. Thermogravimetric analysis of 2@PMMA between $30{ }^{\circ} \mathrm{C}$ and $600^{\circ} \mathrm{C}$. 


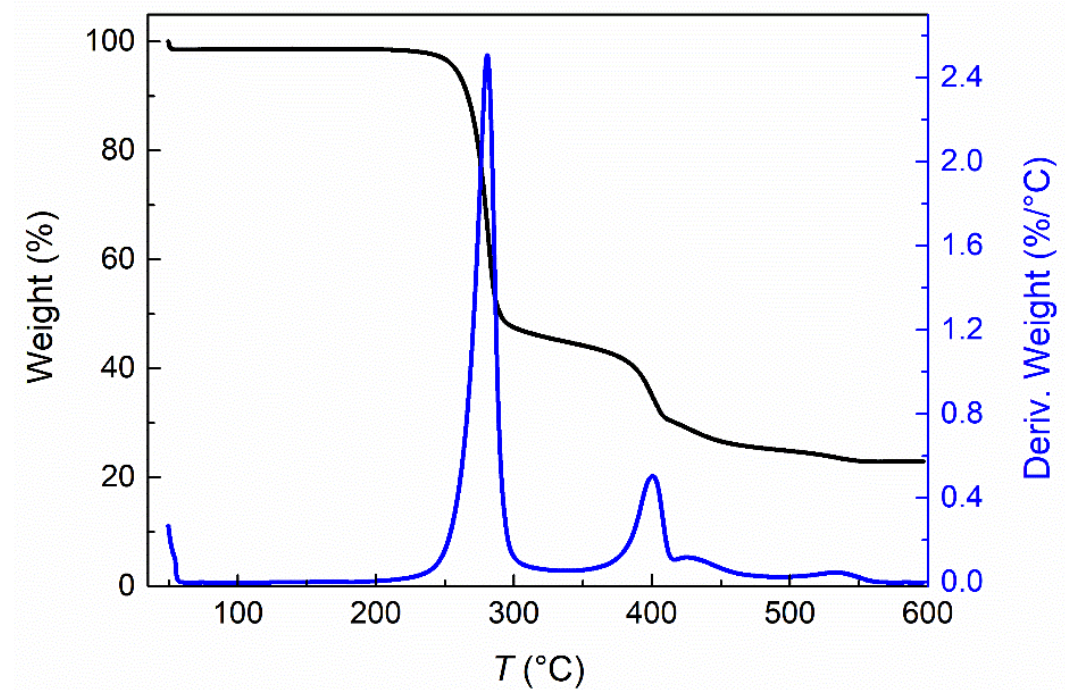

Figure S20. Thermogravimetric analysis of 3 between $30^{\circ} \mathrm{C}$ and $600^{\circ} \mathrm{C}$.



Figure S21. Thermogravimetric analysis of 3@PMMA between $30{ }^{\circ} \mathrm{C}$ and $600^{\circ} \mathrm{C}$.

10) Absorption spectra 


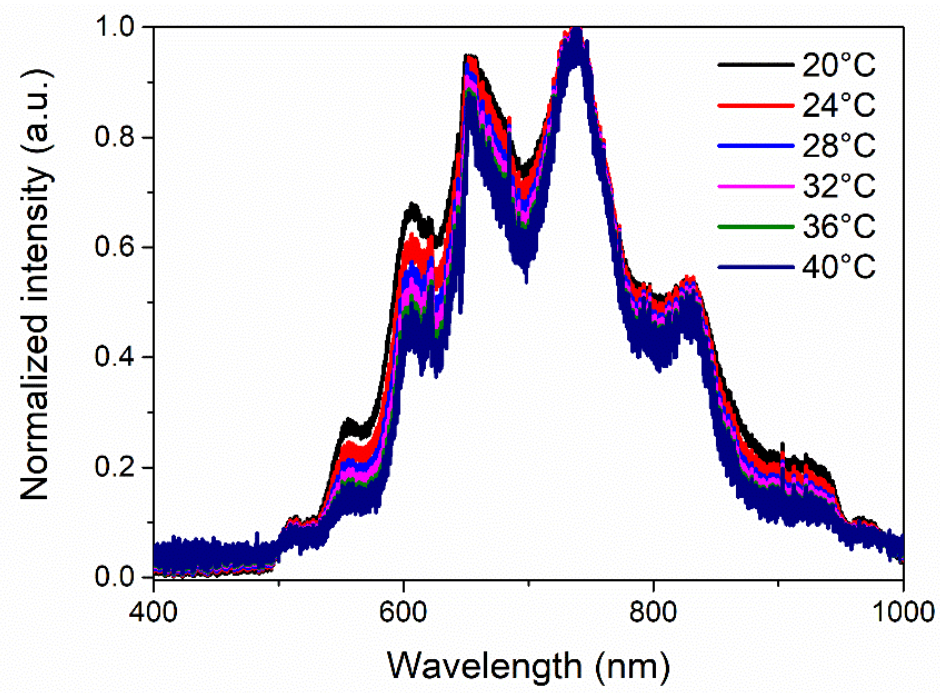

Figure S22. Absorption spectra for 1@PMMA at different temperatures.



Figure S23. Absorption spectra for 2@PMMA at different temperatures.

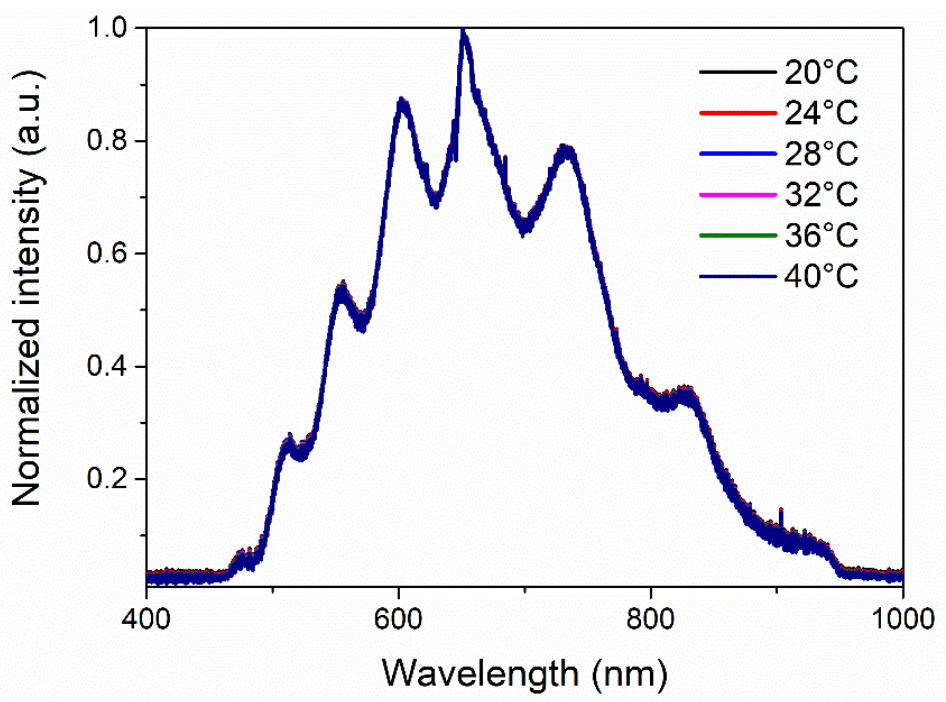


Figure S24. Absorption spectra for 3@PMMA at different temperatures.

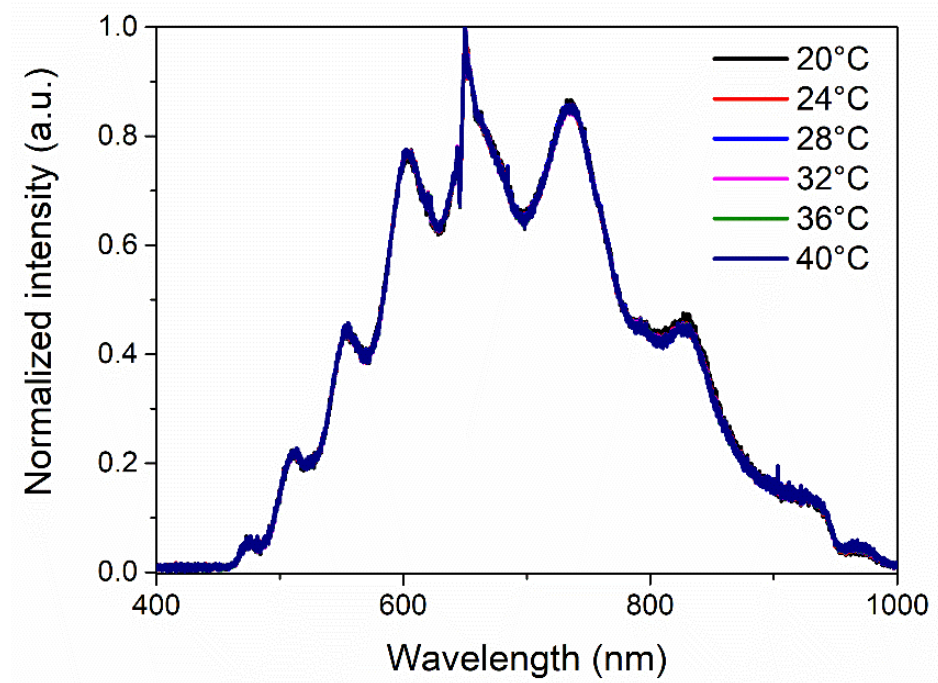

Figure S25. Absorption spectra for PMMA at different temperatures.

\section{1) First experimental setup}
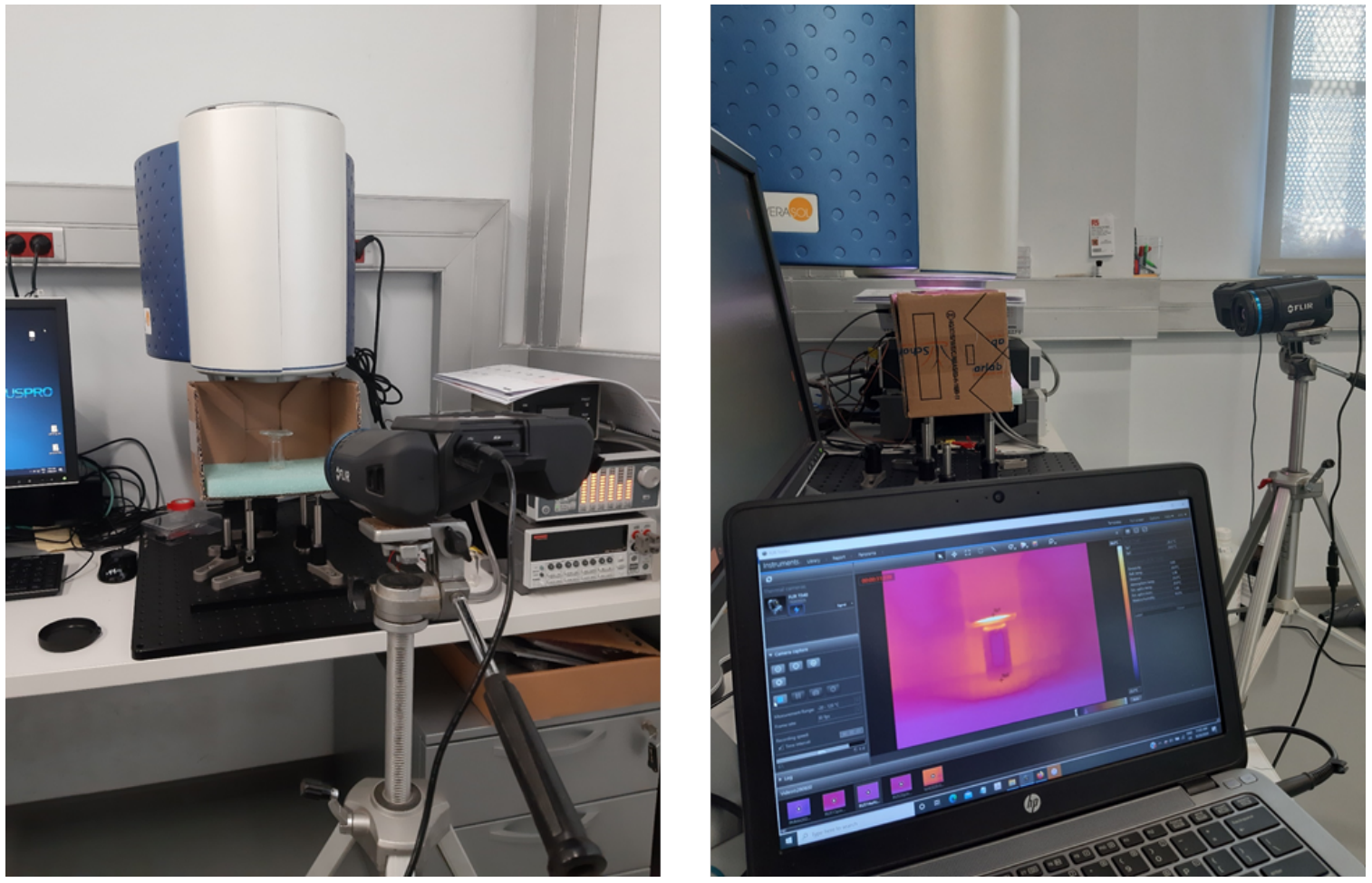

Figure S26. First experimental setup. 


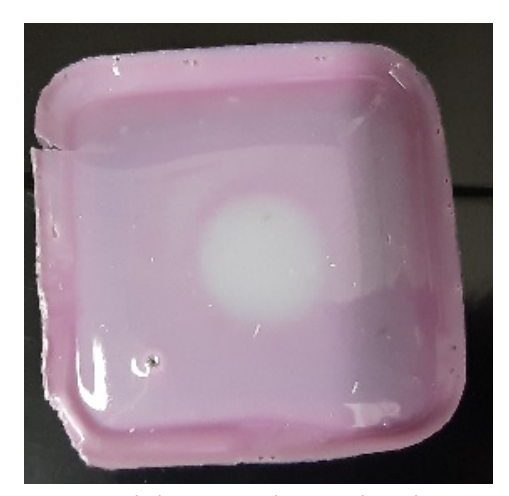

Figure S27.1@PMMA after exposition to the solar lamp, where the HS and LS phases can be seen by bare-eye.

\section{2) Second experimental setup}

The second experimental setup consists on two Peltiers, which are in contact with a copper sheet of $0.5 \mathrm{~mm}$, that acts as a sample holder. A round hole $(\mathrm{d}=10 \mathrm{~mm})$ is drilled into this copper foil. On top of this there is another copper sheet with a square window (40 $\mathrm{mm} \times 40 \mathrm{~mm}$ ) where the sample is placed. Another sheet, equal to the first one, goes on top of the sample, so that it is sandwiched by copper sheets from all directions, except the hole, that allows the light irradiation to pass through the sample. To avoid heating of the copper foils with the solar simulator, a piece of insulating foam is placed on top, covering the copper sheets, except the transmission aperture. Directly below this orifice, there is an anodized aluminum sensor (area $10 \mathrm{~mm} \times 10 \mathrm{~mm}$; distance from sample: $25 \mathrm{~mm}$ ), surrounded from all sides, except from above, by insulating foam. To eliminate temperature fluctuations coming from the Peltiers, two metal sheets $(225 \mathrm{~mm}$ x $95 \mathrm{~mm}$ $\mathrm{x} 1 \mathrm{~mm}$ ) are placed in between them and the sensor, so the temperature flow is perpendicular to the Peltier-sensor-Peltier direction. The temperature is monitored in the sensor by a thermocouple. Right next to the sample there is another thermocouple attached, but to accurately control the sample temperature the thermal camera is used. The solar simulator is placed on top of this setup (distance to the sample $120 \mathrm{~mm}$ ). 

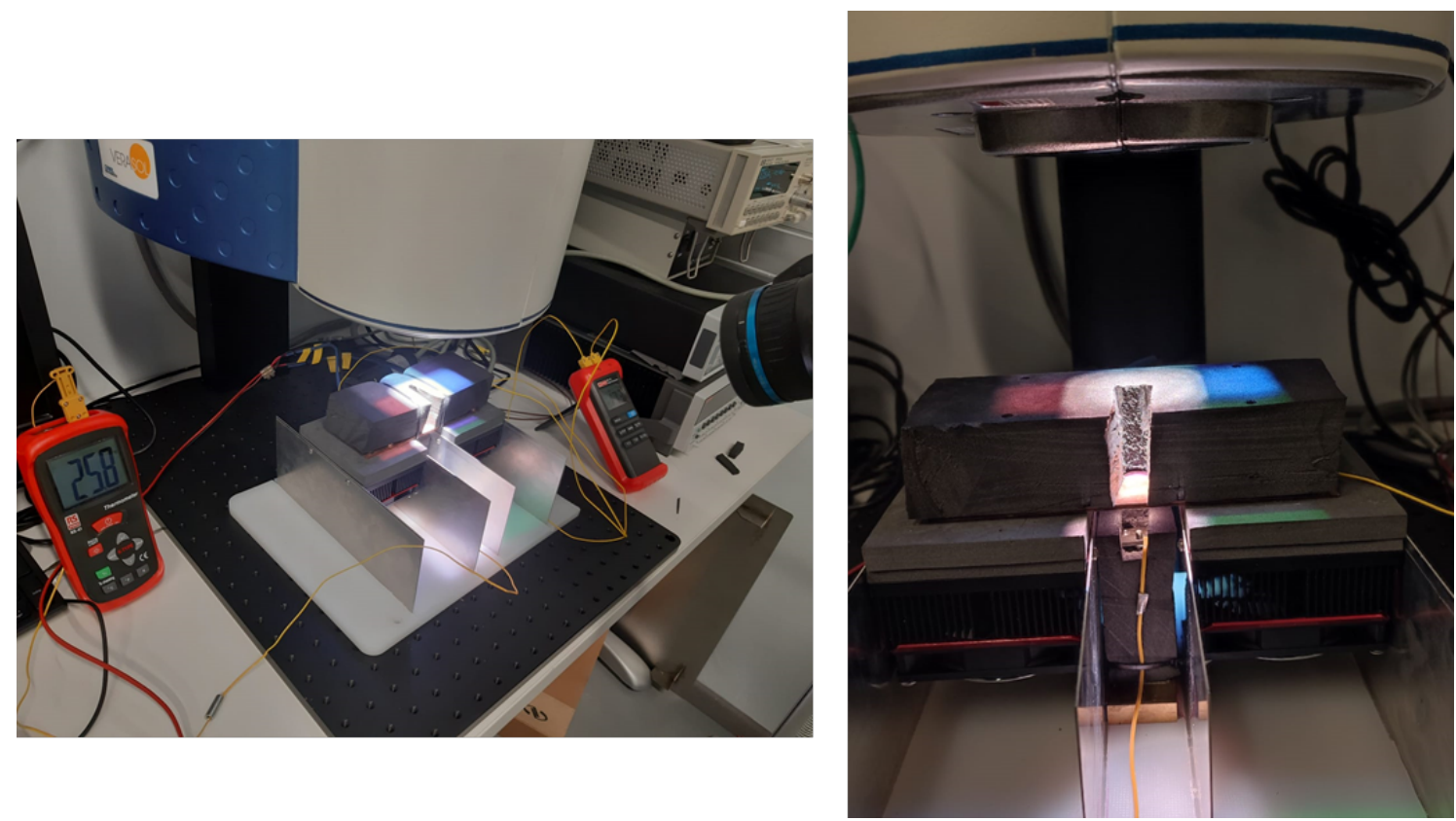

Figure S28. Second experimental setup.

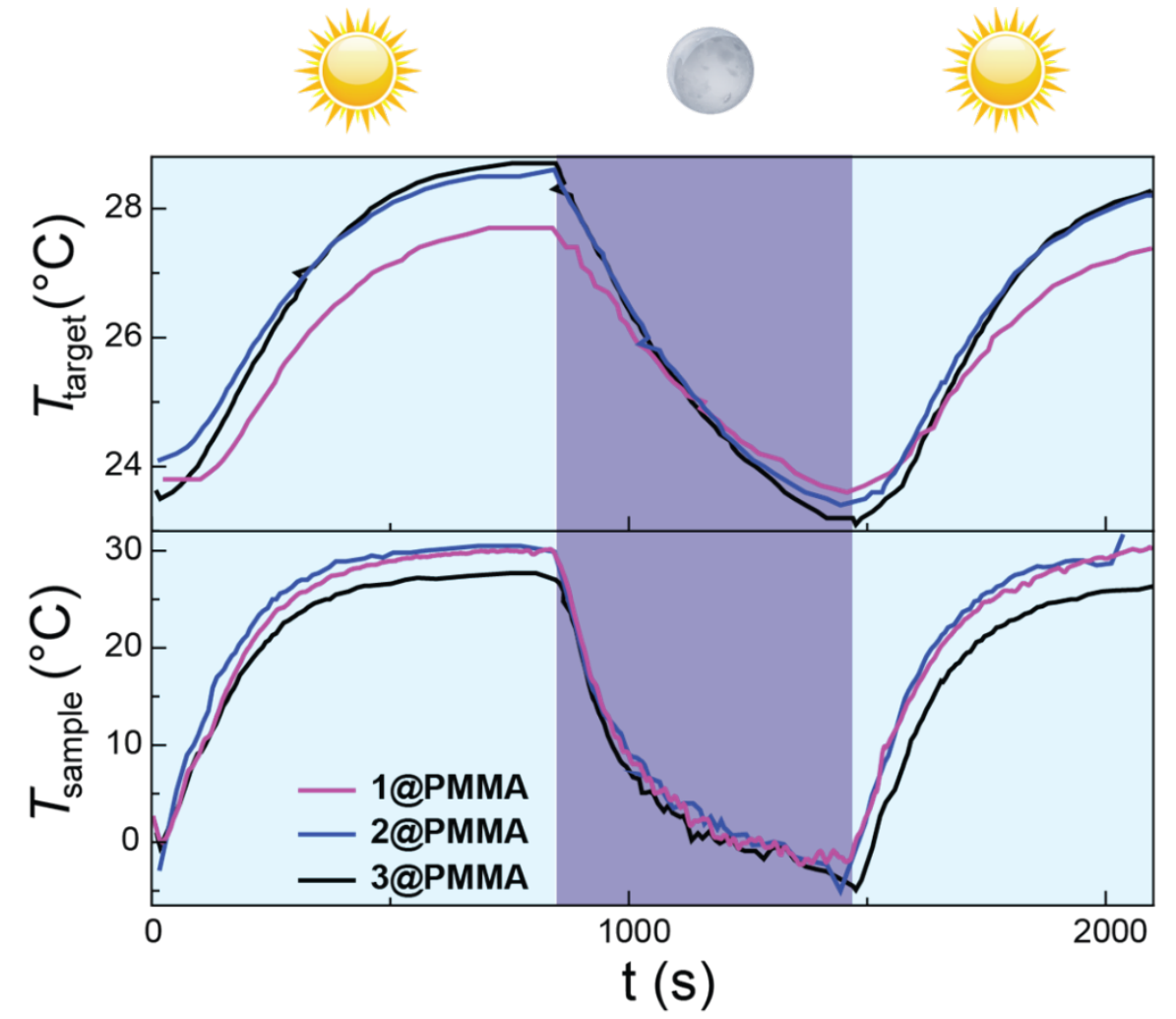

Figure S29. Repetition of the on-off solar simulator cycles experiments. 
a)

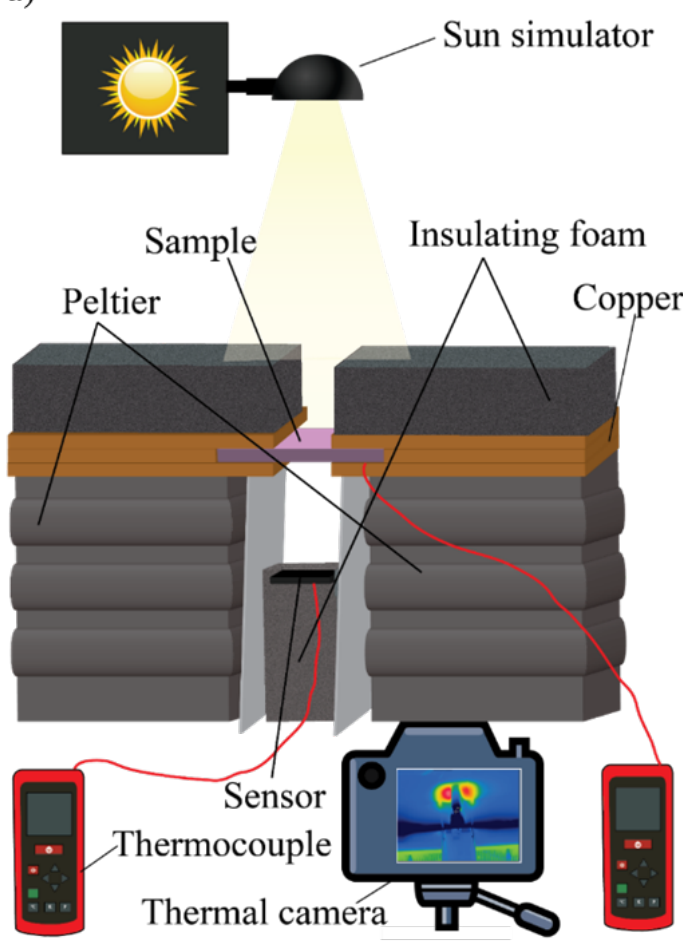

b)

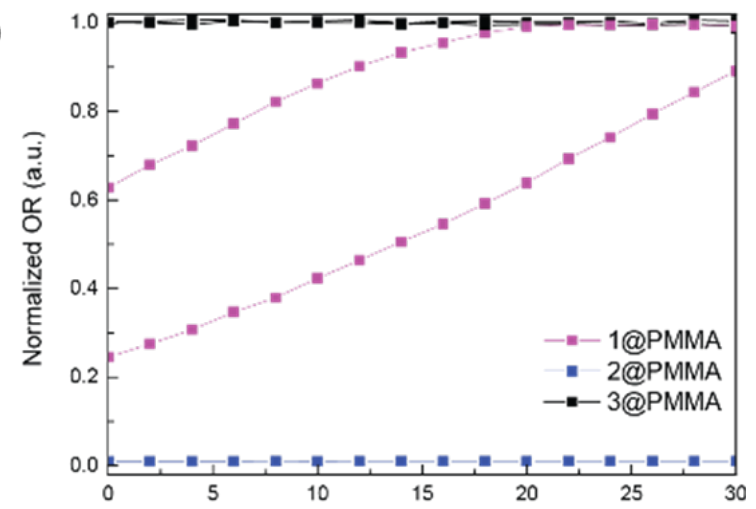

c)

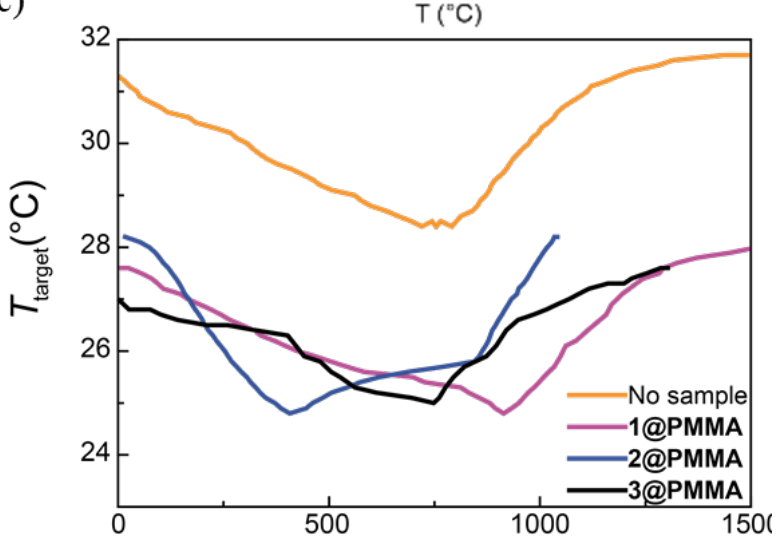

$t(s)$

Figure S30. a) Scheme of the experimental setup. b) Optical reflectivity measurements for 1@PMMA-3@PMMA in the temperature region encompassed by these sunlight exposure measurements. The optical reflectivity has been normalized in respect to 1@PMMA. c) $\mathrm{T}_{\text {target }}$ vs. exposure time with the solar simulator turned on and on-off Peltier cycles. 